\title{
Review \\ Materials Engineering for Flexible Metallic Thin Film Applications
}

\author{
Megan J. Cordill ${ }^{1,2}, * \mathbb{D}$, Patrice Kreiml ${ }^{1, *} * \mathbb{D}$ and Christian Mitterer ${ }^{2} \mathbb{C}$ \\ 1 Erich Schmid Institute for Materials Science, Austrian Academy of Sciences, 8700 Leoben, Austria \\ 2 Department of Materials Science, Montanuniversität Leoben, 8700 Leoben, Austria; \\ christian.mitterer@unileoben.ac.at \\ * Correspondence: megan.cordill@oeaw.ac.at (M.J.C.); patrice.kreiml@oeaw.ac.at (P.K.)
}

check for updates

Citation: Cordill, M.J.; Kreiml, P.; Mitterer, C. Materials Engineering for Flexible Metallic Thin Film

Applications. Materials 2022, 15, 926. https://doi.org/10.3390/ ma15030926

Academic Editors: Michael Stüber and Karsten Woll

Received: 16 November 2021

Accepted: 21 January 2022

Published: 25 January 2022

Publisher's Note: MDPI stays neutral with regard to jurisdictional claims in published maps and institutional affiliations.

Copyright: (C) 2022 by the authors. Licensee MDPI, Basel, Switzerland. This article is an open access article distributed under the terms and conditions of the Creative Commons Attribution (CC BY) license (https:// creativecommons.org/licenses/by/ $4.0 /)$.

\begin{abstract}
More and more flexible, bendable, and stretchable sensors and displays are becoming a reality. While complex engineering and fabrication methods exist to manufacture flexible thin film systems, materials engineering through advanced metallic thin film deposition methods can also be utilized to create robust and long-lasting flexible devices. In this review, materials engineering concepts as well as electro-mechanical testing aspects will be discussed for metallic films. Through the use of residual stress, film thickness, or microstructure tailoring, all controlled by the film deposition parameters, long-lasting flexible film systems in terms of increased fracture or deformation strains, electrical or mechanical reliability, can be generated. These topics, as well as concrete examples, will be discussed. One objective of this work is to provide a toolbox with sustainable and scalable methods to create robust metal thin films for flexible, bendable, and stretchable applications.
\end{abstract}

Keywords: thin films; sputtering; electro-mechanical; flexible

\section{Introduction}

Thin films on rigid substrates are present in the applications and devices people use every day. The mechanical, thermal, electrical, and magnetic properties of thin films often come from the small dimensions. These small dimensional properties translate directly to flexible, stretchable, and bendable devices. From highly advanced foldable mobile phones and thermally resistant multilayers for aerospace applications to more simple uses in food packaging, thin films on compliant polymer substrates are ubiquitous. Some challenges with flexible and bendable applications include depositing films onto compliant and thinner polymer foils and how to properly characterize the electro-mechanical reliability of the flexible systems. Over the last two decades, new knowledge has been obtained about how different thin film deposition methods can be effectively used to fabricate metal and ceramic thin films on polymer substrates as well as advances in how to determine the mechanical and electrical limits of various flexible thin film systems. These methods are more sustainable, requiring no changes to existing thin film deposition infrastructure, as well as being more scalable compared to new, more complex manufacturing methods.

Reviews and other contributions are available about designing flexible thin film devices that focus on how the geometry of lines or thin film transistor (TFT) islands can be designed to create robust devices [1-5]. These advances include the use of meanders, nanowires or nanomeshes, conductive polymers, and wrinkling [6-8]. Here, the focus is to illustrate how metallic thin film engineering can be applied to create long-lasting, and even unbreakable, flexible systems. First, deposition methods to fabricate thin metal films for flexible electronic applications will be introduced, and next the challenges of growing these films on polymer substrates are highlighted (Section 2). Deposition methods are followed by a brief introduction into electro-mechanical testing methods for thin films on polymer substrates (Section 3). In Section 4, several thin metal film materials design examples are summarized, including film thickness, residual stress, microstructure tailoring, the 
significance of thin film architecture, and thin film alloying possibilities. Through these deposition-based strategies, reliable flexible metal films can be created without the need for complicated geometries or additional fabrication steps.

\section{Thin Film Deposition}

Nowadays, numerous methods are available for the deposition of functional thin films, being used for a plethora of applications, such as for wear protection of tools and components, as interconnect lines, adhesion or seed layers, semiconductor films, diffusion barriers, insulating layers and heat sinks in microelectronics, electrode layers with tunable optical and electrical properties in optoelectronics and displays, for energy harvesting in photovoltaics, as self-cleaning photocatalytic films for optical lenses or mirrors, or as permeation barriers for packaging foils. Many of these applications use physical vapor deposition (PVD) techniques, representing a versatile family of techniques for the deposition of high-quality films with tailored multifunctional properties. In particular, sputter deposition methods also enable the growth of thin films at temperatures close to room temperature, making them highly suitable for metallic film deposition on flexible polymer substrates. Today, the majority of thin films are deposited on metal, ceramic, semiconductor, and glass substrates, whereas recently, polymers have gained importance, due to their light weight (being advantageous for automotive applications) and their flexibility (making them highly suitable for wearable/flexible electronics). This section gives an overview on sputter deposition methods for growing thin metal films at low temperatures on flexible substrates, summarizing the present state-of-the-art methods and highlighting some of the challenges of the large-area coating of polymers.

\subsection{Plasmas in Thin Film Deposition}

In PVD processes, the plasma plays a crucial role in enabling the growth of dense thin films at or at least close to room temperature. The plasma fulfills a two-fold task, (i) to generate a vapor phase, e.g., in sputtering, and (ii) to activate thin film growth processes occurring at the substrate. A plasma is generally a quasi-neutral gas containing ions, electrons, and neutrals, which shows a collective behavior in the presence of electromagnetic fields [9]. Technically, a plasma is generated by an electrical discharge, where a voltage is applied to two electrodes placed within a vacuum chamber, which is backfilled with a suitable process gas. As a result of the electrical field, positive and negative charge carriers drift in opposite directions and collisions may occur with all the particles present in the plasma. During elastic collisions, energy is transferred from one particle to another, with a change in the internal energy. Inelastic collisions between an electron of sufficient kinetic energy and a neutral may lead to ionization, leaving behind a positively charged ion and another electron. The average distance a particle can travel without a collision is called the mean free path, which is determined by the number of particles available (which is proportional to the pressure) and the cross-section of the respective collision. At the typical pressures of glow-discharges used for sputter deposition, namely $0.1-1 \mathrm{~Pa}$, the mean free path is in the range of a few $\mathrm{cm}$, with only a few collisions between energetic particles on their way from the vapor source (the cathode) to the substrate (the anode) with typical distances in the $10 \mathrm{~cm}$ range, and the process gas (commonly Ar) will occur.

The degree of ionization, specifically the fraction of ionized species within the plasma, is another important characteristic parameter. A cold plasma, such as is generated in a direct current (d.c.) glow-discharge used for sputter deposition, consists mostly of neutrals, with a degree of ionization, i.e., the number of ions divided by the numbers of ions and neutrals within the plasma, of only $10^{-4}$. In contrast, in a thermal plasma the current within the glow-discharge is increased until the voltage drops. This leads to the local confinement of the plasma within an arc discharge, as used for cathodic arc evaporation with its much higher degree of ionization.

Besides the fluxes of charge carriers within the discharge, the potential distribution plays a decisive role in determining plasma properties. A technical plasma, and therefore, 
the charge carriers present within the plasma, are in contact with grounded objects (e.g., the vacuum chamber) confining the plasma. There, as a result of the mass difference, the flux densities of electrons and ions arriving at surfaces in contact to the plasma are not equal, leading to the development of a potential difference repelling the faster electrons and attracting the slower ions towards the grounded object. Consequently, the plasma is characterized by a positive potential: the plasma potential. If the object in contact with the plasma is not grounded, the arriving electron current results in a negative charging, the floating potential, until a zero-net flux of ions and electrons is achieved. The floating potential is, for example, formed on an electrically insulating substrate surface; it is thus of vital importance to understand film growth on a non-conductive polymer surface.

\subsection{Sputter Deposition}

Sputtering is based on momentum transfer from positively charged highly energetic ions, in most cases Ar ions, to a solid target forming the vapor source (i.e., the cathode in the gas discharge) [10]. The kinetic energy of these Ar ions is given by their electrical charge (in sputtering, they are mainly single charged) and the cathode voltage applied, leading to values in the $100-1000 \mathrm{eV}$ range. These ions impinging on the target surface result in a collision cascade, leading to the ejection of target surface atoms and creating a vapor phase. The low deposition rates of conventional diode sputtering and the excessive substrate heating by electron bombardment can be overcome by the use of magnetrons. There, arranging permanent magnets behind the target, the electrons, and thus the plasma, are confined by the superposition of the electrical field originating from the discharge and the magnetic field in front of the target. In a balanced magnetron, the magnetic field lines loop between the central and the outer magnets, providing an efficient plasma confinement. Unbalancing the magnetic field by providing outer magnets, which are stronger than the central ones, enables the plasma to expand away from the target area and a more pronounced interaction of energetic plasma species with the surface of the growing film [11].

The major benefit of sputtering is that virtually any solid material can be used as a target [12]. The thin film material spectrum can be even more expanded by reactive sputtering of a metallic target in an atmosphere containing reactive gases, such as $\mathrm{N}_{2}$ or $\mathrm{O}_{2}$, which leads to the deposition of nitride or oxide films, respectively. In such cases, a compound surface layer may also be formed on the target surface; this process is called target poisoning. This may lead to a significant reduction of the sputter yield, i.e., the number of target atoms sputtered per impinging ion, which is typically much lower for compounds than for metallic surfaces. Target poisoning can be overcome by the efficient control of the electrical power applied to the targets and the partial pressure of the reactive gas [13]. In many cases, sputtering is done using d.c. discharges, because of low-cost power supplies [14]. There, the formation of electrically less or non-conductive reaction layers, such as oxides, can lead to charging of the target surface and arcing. For electrically less conductive or insulating target materials, pulsed d.c. (operated in asymmetric bipolar mode in the few 10 to few $100 \mathrm{kHz}$ range where short positive pulses result in de-charging of the target surface [15]) and radio-frequency power supplies are used.

\subsection{Thin Film Growth}

Film growth during sputter deposition is a highly non-equilibrium process, with thermodynamic restrictions stemming from low-temperature growth and kinetic restrictions due to high growth rates [16]. Energetic species arriving at the film surface condense at extremely high cooling rates of up to $10^{13} \mathrm{~K} / \mathrm{s}$ [17], which leaves very little time for surface diffusion and finding preferential nucleation or growth sites, before the condensed atoms are overgrown by others. The growth of films with a metallic or ceramic character on polymer substrates typically follows the island growth mode (Volmer-Weber growth) [18], where stable clusters formed on the substrate surface grow in three dimensions. Ultimately, the coalescence of these islands occurs when neighboring islands get in contact, followed by 
the competitive growth of the grains. This growth mode leads to the formation of V-shaped columnar grains, with column boundaries typically crossing the complete film, as exemplified by the scanning electron microscopy (SEM) cross-section prepared by focused ion beam (FIB) milling in Figure 1a [19]. Island growth necessitates-depending on the combination of substrate and thin film material as well as the growth conditions-a certain thickness, before continuous films completely covering the whole substrate surface are formed.
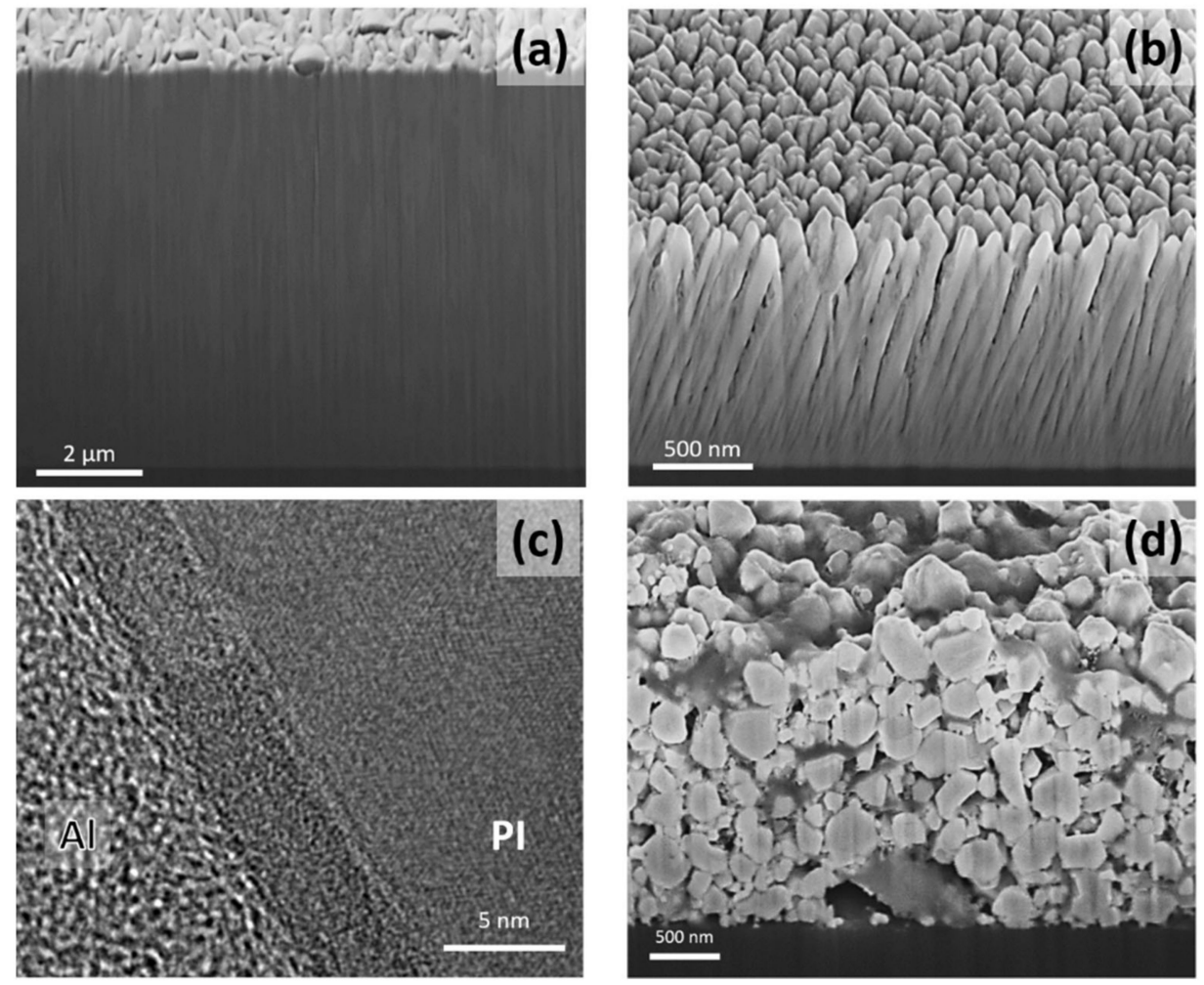

Figure 1. Cross-sections of thin films. (a) SEM micrograph illustrating the fine-columnar growth with columns perpendicular to the substrate surface of a film with a composition of $\mathrm{Mo}_{0.72} \mathrm{Al}_{0.17} \mathrm{Ti}_{0.11}$ deposited directly in front of a rotatable $\mathrm{Mo}_{0.70} \mathrm{Al}_{0.20} \mathrm{Ti}_{0.10}$ target and (b) the open-voided columnar growth of a film grown from the same target and using the same deposition parameters under inclined conditions resulting in a composition of $\mathrm{Mo}_{0.67} \mathrm{Al}_{0.23} \mathrm{Ti}_{0.10}$ [19]. (c) Transmission electron microscopy cross-section of an Al film thermally evaporated on a polyimide (PI) substrate, clearly indicating the modified near surface zone formed during film deposition (courtesy of B. Putz, C. Gammer, B. Völker). (d) SEM micrograph of a Cu film deposited by inkjet printing.

Since the early stages of PVD [20], thin film microstructures have been classified in structure zone models [21], where the thermal and kinetic activation leads to growth governed by the competition of atomic shadowing and diffusion processes. At low substrate temperatures, the less pronounced surface diffusion of the film forming species can be enhanced by atomic scale heating due to the kinetic energy of the species arriving at the film surface. This is typically promoted by low gas pressures, resulting in a high mean free path and less pronounced energy loss of sputtered species and by applying a negative bias voltage to the substrate, this accelerates the $\mathrm{Ar}^{+}$ions to bombard the film surface [22].

\subsection{Large-Area Deposition}

A key for the success of sputter deposition is its scalability, enabling lab-scale to high-throughput large-area film deposition. Planar magnetrons have been dominating the last five decades, having either a round or rectangular shape, with target surface areas in the low $\mathrm{cm}^{2}$ range up to several $\mathrm{m}^{2}$. There, the plasma confinement in front of the target results in inhomogeneous target erosion, where only $20-40 \%$ of the target material are vaporized before the erosion groove approaches the target thickness [12,23]. 
For better target utilization, and-equally important-to reduce downtimes for target replacement in large-area deposition, sophisticated magnet configurations with magnetic fields varying over time are used [24]. In large-area deposition, rotatable cylindrical magnetrons, where a tube target is permanently rotating through the magnetic field, thus continuously sputtering a fresh target surface, are gaining importance. This enables on the one hand target utilization up to $80 \%$, and, on the other hand, efficient target cooling allowing the application of high sputtering powers without overheating the target [25].

As a result of low process gas pressures, sputter deposition is a line-of-sight process, which means that only those areas facing the sputtered target surface will be coated. Using planar targets with their inherently inhomogeneous erosion leads to local thickness differences even in front of the target surface [23]. For both planar and rotatable magnetrons, the coating of large-area substrates (for example, the most recent 10.5 generation display glass dimension is $2940 \times 3370 \mathrm{~mm}^{2}$ [26]) necessitates their permanent oscillation in front of the targets. This, however, results in periodic changes of the direction of the flux of film-forming species arriving at the substrate surface varying permanently between perpendicular and glancing angle deposition, which will also cause periodic variations of the growth rate. In addition, the kinetic energy of these species varies cyclically with the permanent variation of the distance between target and substrate, which affects the number of collisions of sputtered species with the process gas. Consequently, film growth on oscillating substrates varies from a flux of highly energetic species arriving perpendicular to the substrate surfaces to a low-energy flux arriving under glancing angles, leading to films consisting of areas with dense columns perpendicular to the substrate and openvoided inclined columns (compare Figure 1a,b) [19].

There is a recent trend to add more and more functionalities to thin metallic films, for example, to achieve a suitable combination of oxidation resistance with electrical and optical properties, demanding complex film alloy designs with multiple elements [27]. While in lab-scale experiments combinatorial sputtering from multiple magnetrons using different single-element targets is widely used to identify "sweet spots" in the chemical composition [28], large-area deposition necessitates sputtering from multiple-element targets. There, translating the target composition directly into the thin film composition is often challenging due to selective sputtering and gas phase scattering of the individual elements [19]. As an example, both films presented in Figure $1 \mathrm{a}$ and $\mathrm{b}$ are sputtered from the same rotatable $\mathrm{Mo}_{0.70} \mathrm{Al}_{0.20} \mathrm{Ti}_{0.10}$ target in the same deposition system using the same process parameters. The film deposited directly in front of the target (Figure 1a) has a chemical composition of $\mathrm{Mo}_{0.72} \mathrm{Al}_{0.17} \mathrm{Ti}_{0.11}$, it undergoes loss of $\mathrm{Al}$ due to the enhanced scattering of light $\mathrm{Al}$ atoms colliding with the Ar process gas. For the film shown in Figure 1b, which was grown under inclined conditions to simulate substrate oscillation with a factor of 2.7 higher target-substrate distance, a composition of $\mathrm{Mo}_{0.67} \mathrm{Al}_{0.23} \mathrm{Ti}_{0.10}$ is obtained, indicating that for these high distances the pronounced scattering of Mo atoms also takes place [19]. As a consequence, metal films composed of multiple elements, even when sputtered from multiple-element targets, will have variations in morphology and chemical compositions when grown on oscillating substrates. The deposition of highquality metal films on flexible polymer substrates poses some more challenges. While in many research studies polyimide (PI) substrates with their high thermal stability of up to more than $300{ }^{\circ} \mathrm{C}$ have been used, polyesters such as polyethylene terephthalate (PET) or polyethylene naphthalate (PEN) show advantages with respect to optical clarity, but suffer from low glass transition temperatures of 80 or $150{ }^{\circ} \mathrm{C}$, respectively [29]. The softening of polymers at elevated temperatures may also lead to the release of gas trapped in the polymer, which may deteriorate film adhesion [30]. This means that thermal overloads of the substrates, by heat radiation from the magnetron plasma running at high power or by energetic particle bombardment of the substrate, need to be avoided. In a recent study, Jörg et al. have shown that sputtering a single rotating cylindrical molybdenum target with dimension $\varnothing 150 \mathrm{~mm} \times 600 \mathrm{~mm}$ at $10 \mathrm{~kW}$ d.c. power under close to industrial conditions results in a rise of the substrate temperature up to $300{ }^{\circ} \mathrm{C}$ within $250 \mathrm{~s}$ [31]. On a more 
local scale, the bombardment of the polymer surface during substrate pre-treatment or in the early film growth stage with energetic species may alter the near surface zone of the polymer, thus affecting adhesion [32]. An example for the near surface zone of a PI substrate modified by thermal vapor deposition of an $\mathrm{Al}$ film is shown in Figure 1c, where clearly a few nanometers-thick interlayer is visible. Tailoring of such interlayers might potentially be used to enhance adhesion. Consequently, such a flexible thin film system should be treated as composed of three layers, the polymer substrate, the interface zone, and finally the film itself.

Avoiding overheating of thermally sensitive substrates means that film growth occurs with low thermal activation, leading to a dominating influence of atomic shadowing on the growth of the nucleated islands (see Section 2.3). Under these growth conditions, deposition of dense films with the typical low thicknesses of a few $10 \mathrm{~nm}$, e.g., for interconnect lines, diffusion barriers, or adhesion layers, is challenging.

Another limitation in film growth stems from the low electrical conductivity or even insulating nature of the polymer substrates. In many cases, large-area sputter deposition is performed using grounded substrate holders that do not have the possibility to apply a negative substrate bias voltage to kinetically activate film growth. Subjecting the polymer substrate to the plasma means that its surface is exposed to a zero-net flux of ions and electrons, where-as a result of the different ability to be accelerated within the electrical field - charging of the polymer surface up to the negative floating potential (see Section 2.1) occurs. The proceeding growth and coalescence of an electrically conductive film forming islands then leads to the de-charging of the surface, changing the conditions of bombardment of the growing film with charged species. On a large-area substrate oscillating in front of the plasma of the magnetrons, local charging and de-charging effects will lead to changing conditions during the early film growth stage.

Finally, sputter deposited films are typically under a tensile or compressive stress state stemming from thermal (which are assumed to be low because of the necessary low substrate temperatures), intrinsic (stemming from growth defects), and extrinsic contributions (originating from structural misfit, phase transformation, precipitation, plastic or creep deformation, chemical reactions, etc.) [33]. Tensile stresses exceeding the cohesive energy of the film will result in crack formation, whereas compressive stresses may lead to spontaneous delamination buckling, provided that the film adhesion is sufficiently low [34]. Careful optimization of the deposition conditions for stress minimization is necessary to avoid the unacceptable deterioration of the film/polymer system.

\subsection{Other Thin Film Deposition Methods}

Despite the challenges associated with the sputter deposition of thin films onto polymer substrates summarized in Section 2.4 and high investment costs of vacuum deposition systems, the scalability from lab-scale research to high-throughput large-area deposition, excellent process controllability, and the versatility in terms of available film materials and their microstructures combined with the ability to grow high-quality films at temperatures compatible with thermally sensitive substrate materials make this technique unique [18]. Besides vapor deposition, other processes using liquid precursors are used to coat polymer substrates such as spray-, dip-, and spin-coating. These techniques are popular in research, due to their low investment costs and easy process optimization, but some of them are inherently nonuniform over large areas, which poses challenges on scalability [35]. Among these techniques, dip-coating is suitable for roll-to-roll coating, enabling high-throughput film deposition on thin flexible polymers [36].

Inkjet printing represents an attractive technique for patterning, or the "direct writing" of well-defined thin film metal lines with widths down to the micrometer range, thus avoiding masks [37]. A drawback of such solution-based methods is the use of solvents carrying metallic nanoparticles and binders [38], or self-reducing methods [39], which necessitate post-deposition curing to remove solvents and to sinter the nanoparticles. Even then, films are significantly less dense than sputter deposited films, as evidenced 
by the SEM cross-section of a printed $\mathrm{Cu}$ film in Figure 1d. Consequently, the electrical conductivity of these printed lines is well below that of the corresponding bulk metal [40].

The various deposition methods and parameters provide a wealth of opportunities to tailor thin metal films. After deposition, the flexible metallic films must be properly characterized electrically and mechanically. Such characterization techniques are relatively new to the field. The subsequent sections provide an introduction into the electro-mechanical testing of thin metal films deposited onto flexible polymer substrates (Section 3) and a discussion of some thin film material design aspects based on metallic thin film deposition methods to optimize their performance for flexible electronic applications (Section 4). In agreement with the importance of sputter deposition processes, most of the examples chosen will be based on sputter deposited metal films.

\section{Electro-Mechanical Testing}

The most efficient way to examine the electrical and mechanical behavior of flexible metal film systems is to use uniaxial tensile straining methods. The tensile straining of metal or ceramic/oxide films on polymer substrates can also be referred to as fragmentation testing or periodic cracking and was initially used in composites and ceramic films on metal substrates [41-43]. With the introduction of flexible electronics at the turn of the 21st century, the same technique was applied to metal-polymer and ceramic-polymer systems [44-48]. The main concept behind fragmentation testing is the shear lag model $[41,42,49]$ that can be used to determine the interfacial shear stress, $\tau_{\text {IFSS }}$, to quantify the stress the interface can carry (Equation (1)):

$$
\tau_{\text {IFSS }}=\pi h_{f} \sigma_{\text {frac }} / 2 \lambda_{\text {sat }} .
$$

In Equation (1), $\sigma_{\text {frac }}$ is the initial fracture stress of the film, $\lambda_{\text {sat }}$ is the average linear crack spacing at saturation (when no further cracks form), and $h_{f}$ is the film thickness. The initial fracture stress is best measured with X-ray diffraction (XRD); however, many groups have also used Hooke's law and the observed fracture strain (i.e., $\sigma_{f r a c}=E_{f}$. $\varepsilon_{f r a c}$ with $\varepsilon_{f r a c}$ the observed fracture strain, and $E_{f}$ the elastic modulus of the film). An important aspect to remember is that in order to apply the shear lag model, the ratio between the maximum and minimum crack spacings at saturation must be two. Only then is the shear lag model applicable [41,49]. Small changes in the film thickness or large surface roughness have been shown to alter this ratio for brittle films on metal or polymer substrates [50,51]. In these cases, the neighbor ratio can be applied [50,52]. The neighbor ratio evaluates the crack spacing on either side of a crack. With a neighbor ratio value around two and lower, the film/polymer system can be evaluated with the shear lag model and values much higher than two indicate that the shear lag model cannot be used. In the cases it cannot be used, the most common reason is that the film fragments on the polymer substrate do not remain parallel to the straining direction. Instead, the fragments bend into the more compliant polymer substrate [51,53] (Figure 2) and cause an inhomogeneous stress transfer at the interface. Substrates with low elastic modulus values, such as PET or PEN, are more likely to have significant fragment bending compared to other substrates with higher elastic moduli, such as PI which ranges from 3 to $9 \mathrm{GPa}$.
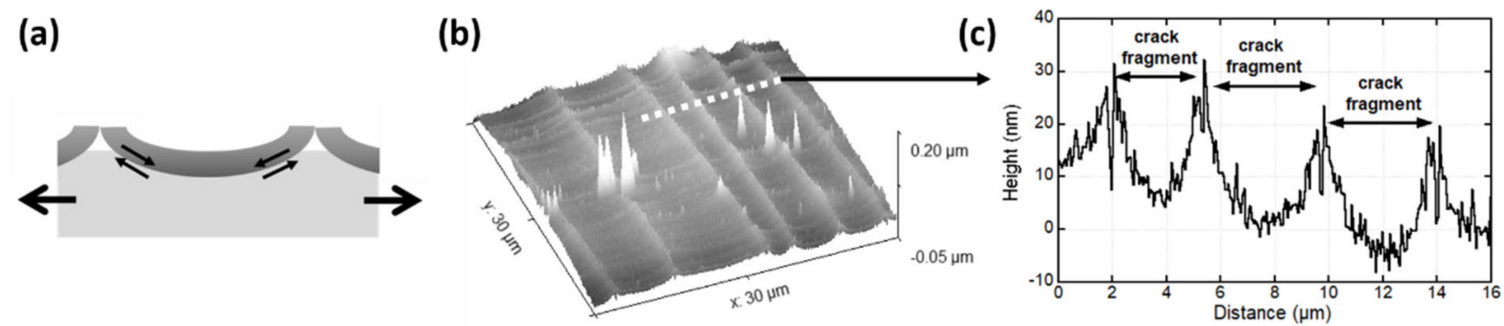

Figure 2. (a) Schematic diagram of fragments bending in cross-section, (b) 3D atomic force microscopy height image of crack fragments in a $200 \mathrm{~nm}$ sputter deposited Cr film on PI at $10 \%$ strain. White dashed line indicates the profile in (c). 


\subsection{Brittle Film Behavior}

The tensile straining of metal films on polymer substrates can be straightforward depending on the type of film system being examined. Films or layers that behave in a brittle manner are the easiest film systems to interpret because only two things can occur: (1) fracture followed by (2) delamination (Figure 3a-c). Brittle films, generally body-centered cubic (BCC) or hexagonal-closed packed (HCP) metals, such as single layers of $\mathrm{Cr}$, Mo, Ti, Ta, along with indium tin oxide and other oxides [31,51,52,54-59], and even metallic multilayers and printed films [60-67] will easily fracture at low applied strains. With in-situ or intermittent imaging of strained samples using optical light microscopy, SEM, or confocal laser scanning microscopy (CLSM), the fractures of films in the form of through thickness cracks (TTCs), also called channel cracks, are observed as well as delamination buckles that form between the crack fragments. At low applied strains $(<1-2 \%)$, cracks will initially form perpendicular to the straining direction. The strain at which cracks are first observed to form is referred to as the crack onset strain (COS) or the fracture strain, $\varepsilon_{\text {frac }}$. Cracks will continue to form with continued straining until a saturation crack spacing, $\lambda_{\text {sat }}$, or saturation crack density, $1 / \lambda_{\text {sat }}$, is reached (Figure $3 \mathrm{~d}$ ). In general, thinner films have higher crack densities (smaller crack spacings) and thicker films have lower crack densities (larger crack spacings). Delamination occurs at much higher applied strains (approximately 8-12\% strain, depending on the film thickness and substrate) usually after the film fragmentation (cracking) has reached a saturation $[51,68,69]$. Delaminated areas, also called buckles, of the film are observed between crack fragments parallel to the straining direction and form because a compressive stress high enough to cause delamination is created due to the difference in Poisson's ratio between film and substrate under uniaxial tensile straining. These buckles can be used to quantify the adhesion energy of the metal-polymer interface [55].
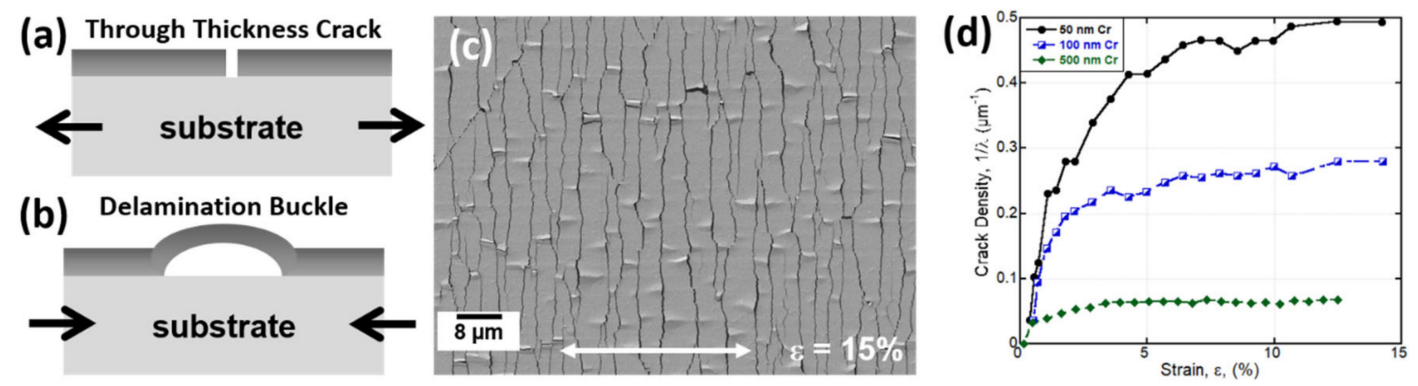

Figure 3. Schematic diagram of (a) through thickness cracks (channel cracks) that form perpendicular to the straining direction and (b) delamination buckles which form parallel to the straining direction. (c) SEM micrograph of a $100 \mathrm{~nm}$ sputter deposited Cr film strained to $15 \%$ to illustrate cracking and delamination of the film. White arrow indicates the straining direction. (d) Crack density evolution for three sputter deposited Cr films (50, 100, $500 \mathrm{~nm})$ on PI illustrating the effect of film thickness.

\subsection{Ductile Film Behavior}

Compared to the brittle film systems that easily fracture and delaminate, ductile film systems will undergo plastic deformation before cracks form. Ductile metals, such as face-centered cubic (FCC) $\mathrm{Au}, \mathrm{Ag}, \mathrm{Al}$, or $\mathrm{Cu}$, are typically used as conductors in flexible electronics or as reflectors in multilayer insulators and optical solar reflectors. Uniaxial straining of single ductile metal layers has a different set of mechanisms than brittle metal films. The main difference is that ductile films can plastically deform more than their brittle counterparts. Therefore, instead of observing the fracture at low applied strains, a deformation onset strain (DOS or $\varepsilon_{d e f}$ ) is observed and corresponds to the initial necking, or localized deformation, of the film (Figure $4 \mathrm{a}-\mathrm{c}$ ). With further applied strain, the necks can become TTCs; however, not all necks will become TTCs [70]. In single ductile films, necking will initiate at the surface. In-situ straining of single ductile layers is best performed with a 
3D surface imaging method, such as atomic force microscopy (AFM) or CLSM. These two methods allow for the determination of the neck or TTC depth $[70,71]$.
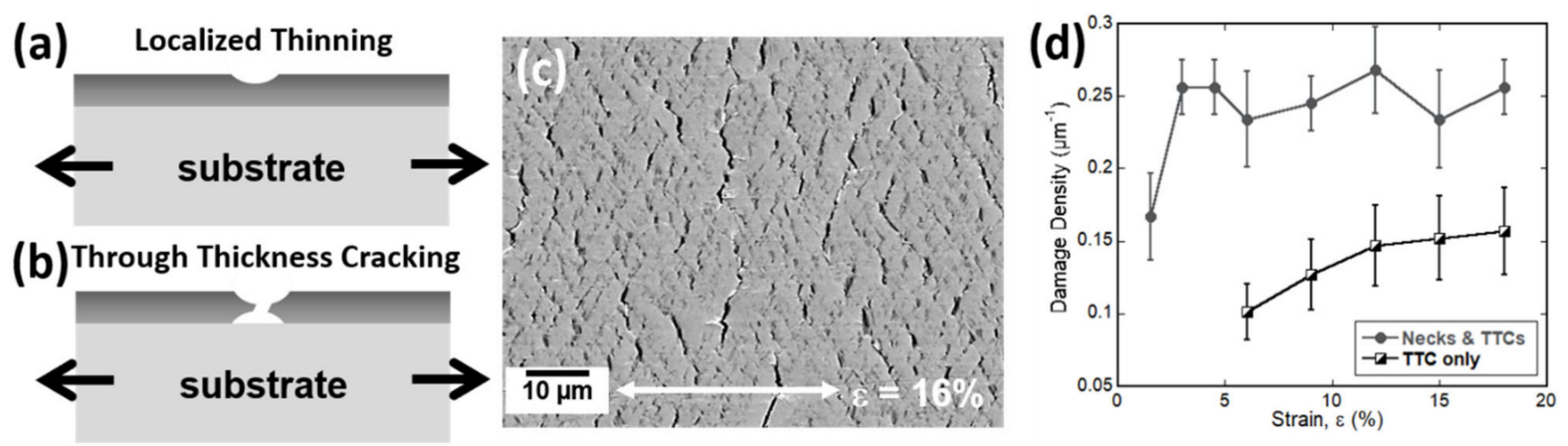

Figure 4. Schematic diagram of (a) localized thinning (also called necking) that first forms when a ductile metal film is strained. With continued straining (b) many of these areas will become TTCs. (c) SEM micrograph of $200 \mathrm{~nm}$ electron beam evaporated $\mathrm{Cu}$ film strained to $16 \%$ to illustrate localized necking and TTC formation (black lines) of the film. White arrow indicates the straining direction. (d) TTC and damage evolution of a $200 \mathrm{~nm} \mathrm{Cu} / 10 \mathrm{~nm} \mathrm{Cr}$ bilayer film system roll-to-roll sputter deposited on PET. The combined damage density of necks and TTC spacing is higher and starts before TTC cracks form.

For single layer ductile films, the deformation is observed to start at the surface. Therefore, AFM and CLSM are excellent imaging techniques to determine the depth of the necks or TTCs using the $\Delta / h$ ratio, where $\Delta$ is the depth of the damage (neck or TTC), and $h$ is the film thickness. In AFM and CLSM, the probe form might limit access to the deepest part of the crack [72]; therefore, a neck is defined when the $\Delta / h$ ratio is less than $10-15 \%$ of the film thickness and a TTC when the $\Delta / h$ ratio is greater than $10-15 \%$ of the film thickness, depending on the surface roughness of the film $[70,71,73,74]$. The evolution of the ductile deformation, also called damage, of a film can be quantified similar to crack spacing (Figure 3d). Damage always starts first, followed by TTC formation (Figure $4 \mathrm{~d}$ ). The damage density will be higher than the TTC density because the damage density includes both necking and TTC sites, while TTC density is only the density of TTCs. Additionally, with in-situ AFM or CLSM the TTC closure, when the tensile load is removed, it can be quantified [73].

\subsection{Electrical Behavior}

For flexible electronics, the electrical behavior needs to be measured as a function of applied strain. In-situ resistance measurements are the optimum method to measure the electrical response as a function of applied strain. Lu, Wang, and Vlassak [75] introduced the constant volume approximation as a way to determine the COS of metal or conductive ceramics supported by polymer substrates. The constant volume approximation evaluates the electrical properties of a material as a function of strain, as follows (Equation (2)):

$$
R / R_{0}=\left(L / L_{0}\right)^{2}=(1+\varepsilon)^{2},
$$

where $R$ is the measured resistance, $R_{0}$ the initial resistance before straining, $L$ the gauge length, $L_{0}$ the initial gauge length, and $\varepsilon$ the strain [75]. Any deviation from the constant volume approximation is related to changes in the material initiating from the geometrical changes due to straining [76]. This could be an increase or decrease caused by defects, such as TTCs, grain growth, high residual stress, or phase changes. From the constant volume approximation, the formation of structural damage, such as TTCs, can be indicated. For brittle films a strong and sudden increase in $R / R_{0}$ or $\Delta R / R_{0}$ signals that at least one TTC is long enough to hinder the electric current flow (Figure 5a). Many researchers have reported that the sudden increase in resistance is correlated to the observed crack formation 
in brittle films [77-83]. The increase in the electrical resistance of ductile film systems, on the other hand, does not always signal a fracture. DOS occurs somewhere between necking and TTCs' formation because TTCs are much shorter in ductile films and necks can still conduct currents. In the case of ductile film systems, a 10-20\% deviation from the constant volume approximation has been used as a failure criterion [80]. This criterion avoids any opinions as to how "an increase" from the constant volume approximation could be defined (Figure 5a). In Figure 5, the electrical response of a single $30 \mathrm{~nm}$ Mo film is compared to $\mathrm{Mo} / \mathrm{Al}$ bilayers with various $\mathrm{Al}$ thicknesses (thickness ratios of 1:1, 1:3, 1:5, and 1:10, with a $30 \mathrm{~nm}$ Mo constant) to illustrate different responses due to ductile Al film thickness.

(a)

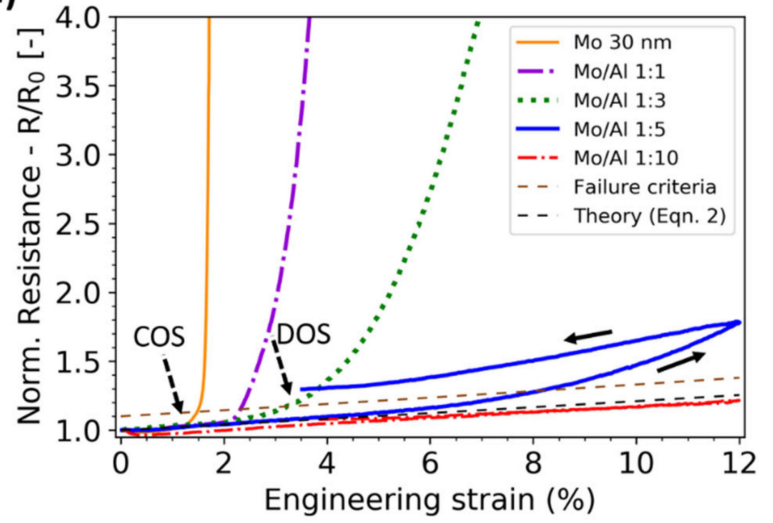

(b)

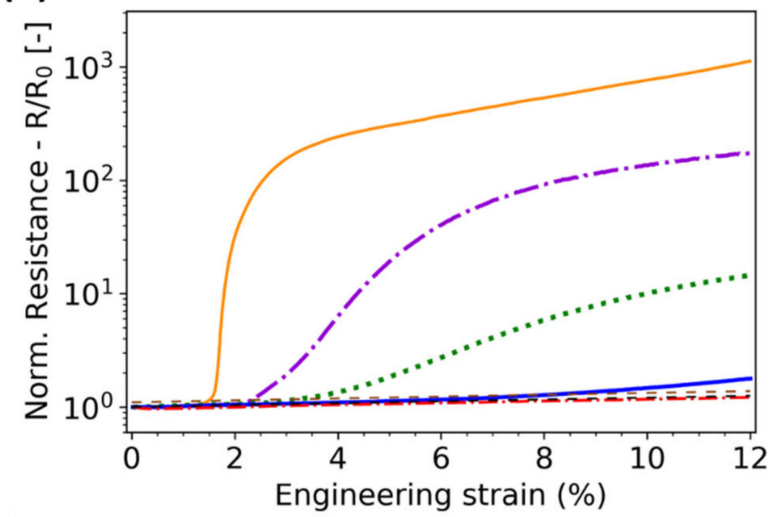

Figure 5. (a) Example of brittle and ductile electrical behavior in sputter deposited Mo and Mo/Al bilayers with increasing $\mathrm{Al}$ thickness (Mo:Al layer thickness ratio) as a function of applied strain. Deviation from the constant volume approximation generally is referred to as the COS or DOS. Note that the more ductile bilayers have a variety of responses compared to brittle $30 \mathrm{~nm}$ Mo film. (b) At high applied strains, the resistance does not reach a distinct plateau even though the crack or damage density saturates (note log scale). Only loading data shown for clarity. Data taken from [80].

The electrical behavior is considered to be a global measurement, considering ALL necks and TTCs that form between the contact grips (or contacts) used for straining. In-situ AFM, CLSM, and even XRD experiments have a finite, or local, area that is observed or measured during straining. Thus, the local measurements may not tell the whole story of the global electrical response. What the electrical DOS indicates is that a critical density of structural defects is present at a specific applied strain that increases the electrical resistance between the electrical contacts, rather than a distinct COS. The structural defects could be a few long TTCs, multiple short TTCs, or more severe pre-existing defects such as substrate scratches. It is important to understand that while the damage density (TTCs and/or necks) will saturate (Figures $3 \mathrm{~d}$ and $4 \mathrm{~d}$ ), the electrical resistance does not (Figure $5 \mathrm{~b}$ ). It is also beneficial to measure the resistance during loading and unloading of the experiment (Figure 5a, solid blue line, Mo/Al 1:5, with arrows). As the sample is unloaded (downward arrow), the viscoelastic recovery of the substrate occurs and TTCs in the metal film can re-bridge, or close, and help to reduce the measured resistance. FIB cross-sectioning has provided evidence to the crack re-bridging, for example Figure 5 in [76]. Additionally, an in-situ experiment with AFM and electrical resistance by Cordill et al. [73] quantified the resistance recovery and related it to the decrease in TTCs' spacing and increase in deformation (necks and TTCs) spacing. In the early literature, which utilized the in-situ resistance measurement, the maximum resistance at the maximum applied strain was reported with an image of an unloaded film at a different unloaded and recovered strain. Thus, the reported resistance did not relate to the damage or TTC density in the provided image since a portion of the TTC s closed and were no longer visible as TTCs.

A recent development to better understand resistance recovery and crack re-bridging is to use the cracking factor $[84,85]$. This approach uses the electrical resistance and the crack density to estimate an effective crack length, $\ell_{\text {eff, }}$ of the TTCs travelling along the 
plane of the film. Additionally, the electro-mechanical behavior can be expressed by a simple quadratic expression (Equation (3))

$$
R / R_{0}=1+(1 / \sqrt{ } 2) C_{l} \ell_{\text {eff }}+(1 / 2) C_{l}^{2} \ell_{\text {eff }}^{2},
$$

where $R / R_{0}$ is the normalized resistance, $C_{l}$ is the linear crack density, and $\ell_{\text {eff }}$ the effective crack length. There are limitations to the cracking factor approach [84]; however, in general it can be applied to ductile films exhibiting short cracks. The model assumes all cracks have the same length, while in reality there is a distribution of short and long cracks. More research in this area is needed in order to fully understand the information in-situ resistance measurements provide other than a COS or DOS.

It must be noted that in-situ electrical resistance measurements do not provide information about delamination or film buckling. The resistance is measured parallel to the interface that is delaminating (Figure 6). If a buckle forms, the film is still conductive (and more conductive than the polymer substrate). When it is not connected to the substrate there would be no significant change in the measured electrical resistance as it is nearly impossible to decouple the resistance contributions of cracks and buckles in the crack saturation regime. The current flow is also parallel to the direction of buckle formation and would not influence the measurement. Only cracks perpendicular to the measurement are detected. Furthermore, when buckling does occur, it is at high applied strains where the electrical resistance is already quite high due to the presence of TTCs. No additional information is gained at these high applied strains and resistances (Figure $5 b$ ).

(a)

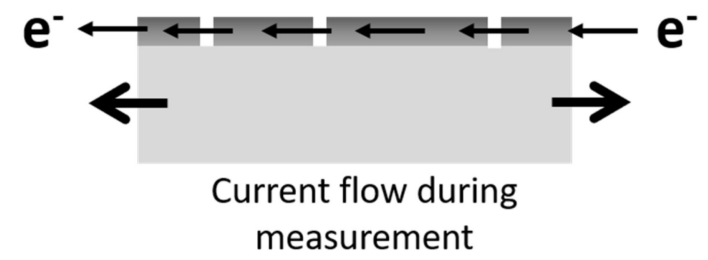

(b) Top of film view with buckles

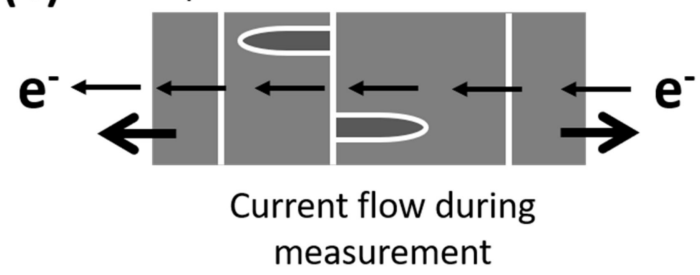

Figure 6. (a) Electrical resistance measurements are performed perpendicular to the TTCs. (b) If the film forms buckles, the measured resistance will not be influenced because buckles are parallel to the measurement direction. Resistance cannot be used to detect delamination.

\subsection{Cyclic Testing}

The cyclic mechanical testing of flexible thin films can be performed in different ways, including uniaxial straining [79,85-92] and bending [93-101]. The uniaxial approach is the more simple experiment to perform and the resistance can be easily added for in-situ measurements [87,102]. It should be noted that with bending, the bending is often applied differently, on a cantilever $[93,99,103]$, in shear creating two zones of damage $[99,101,104]$, at a right angle $\left(90^{\circ}\right)$ to generate one zone of damage [97,98], as well as other configurations $[105,106]$ which makes comparing results between the different methods a challenge. What is known about cyclic loading with in-situ resistance measurements is that when cracks open the resistance increases, and when cracks close the resistance decreases $[66,107]$ (Figure 7). The evolution as a function of the cycle number of the maximum $R / R_{0}$ and minimum $R / R_{0}$ are different for different materials, fabrication methods, microstructures, and loading (uniaxial vs. bending). For most metallic film systems, the $\Delta R=\left(R_{\max }-R_{\min }\right)$ during cycling tends to be small until TTCs form, which significantly increase the $\Delta R$. Exemplary papers on in-situ cyclic tensile testing with resistance will provide more details $[66,85-87]$ including using the cracking factor [85]. For bending, in-situ and intermittent testing methods have been used $[94,95,97,104,108]$. An important concept to know is that measuring the COS or DOS with uniaxial straining and remaining below that value for cycling under bending will not necessarily lead to an unbreakable film system $[108,109]$. 
Only testing for the real application, stretching, or bending, will provide the proper material failure information.

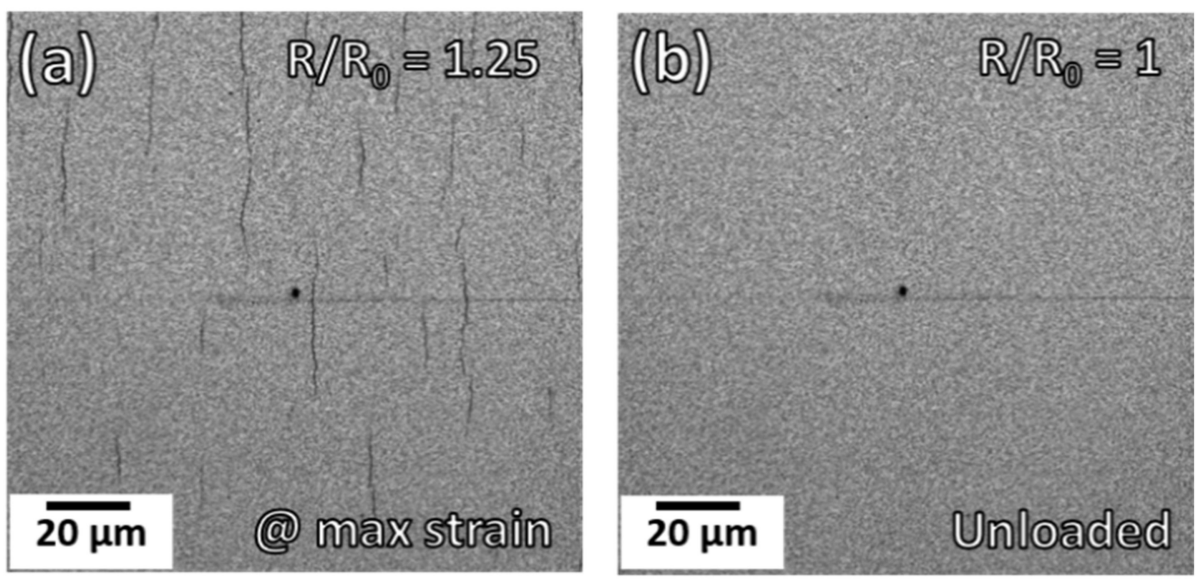

Figure 7. CLSM laser intensity images of a printed Ag film at (a) a maximum applied strain of $2 \%$ having open cracks (black lines) with $R / R_{0}=1.25$. (b) Removing the load returns the $R / R_{0}$ back to its original value of 1 and cracks are no longer visible. (Images courtesy of O. Glushko.).

While more is known and understood about how thin metal films on polymer substrates fail under monotonic tensile straining, the field still has a long way to go (Table 1). Crack formation causing electrical failure is clear and the failure can be quantified with a crack spacing or damage density. However, cyclic tensile straining and cyclic bending are areas that need a clear definition of failure to precisely determine reliability. Is it when the electrical resistance increases by $10 \%$ or $20 \%$ or when a certain value for the electrode resistivity is exceeded? Is it when the first TTC is observed, or, does the saturation damage or crack density define the lifetime? What about the difference between sensing applications and devices? Do these different applications require different failure criteria? These questions can only be answered with the direct collaboration of universities/research institutions with the industry and the full understanding of how mechanical film damage influences the electrical behavior (summarized in Table 1).

Table 1. Summary of benefits, limitations, and possible solutions for electrical resistance-based and cyclic testing.

\begin{tabular}{|c|c|c|c|c|}
\hline Test Type & $\begin{array}{l}\text { Deposition } \\
\text { Method }\end{array}$ & Benefit(s) & Limitation(s) & Solution(s) \\
\hline \multirow[b]{2}{*}{$\begin{array}{l}\text { Electrical } \\
\text { resistance }\end{array}$} & $\begin{array}{c}\text { Sputtering } \\
\text { or Evaporation }\end{array}$ & $\begin{array}{l}\text { - Very good conductivity } \\
\text { with commonly } \\
\text { used parameters } \\
\text { Measure resistance } \\
\text { during straining and } \\
\text { connect to } \\
\text { mechanical damage }\end{array}$ & $\begin{array}{l}\text { Difficult to determine } \\
\text { point of failure (COS vs. } \\
\text { DOS) } \\
\text { Failure criteria based on } \\
\text { increase in resistance and } \\
\text { not damage density } \\
\text { (or both) } \\
\text { Lack of in-situ } \\
\text { resistance understanding }\end{array}$ & $\begin{array}{l}\text { Larger grains have lower } \\
\text { resistance than } \\
\text { smaller grains } \\
\text { More research connecting } \\
\text { electrical resistance } \\
\text { increase with } \\
\text { mechanical damage }\end{array}$ \\
\hline & Printing & $\begin{array}{l}\text { Fast deposition does not } \\
\text { require vacuum or high } \\
\text { temperatures } \\
\text { No lithography necessary, } \\
\text { direct pattern printing } \\
\text { - Measure resistance } \\
\text { during straining and } \\
\text { connect to } \\
\text { mechanical damage }\end{array}$ & $\begin{array}{l}\text { Generally poor electrical } \\
\text { conductivity compared to } \\
\text { sputtered/ } \\
\text { evaporated films } \\
\text { Cracks can form easily at } \\
\text { low to moderate strains }\end{array}$ & $\begin{array}{l}\text { - } \quad \text { Thicker the better } \\
\text { More/longer heat } \\
\text { treatments to promote } \\
\text { sintering of } \\
\text { metal particles }\end{array}$ \\
\hline
\end{tabular}


Table 1. Cont.

\begin{tabular}{|c|c|c|c|c|}
\hline Test Type & $\begin{array}{l}\text { Deposition } \\
\text { Method }\end{array}$ & Benefit(s) & Limitation(s) & Solution(s) \\
\hline Cyclic Testing & Sputtering & $\begin{array}{l}\text { Test application of } \\
\text { relevant } \\
\text { loading conditions }\end{array}$ & $\begin{array}{l}\text { No concrete failure } \\
\text { criteria for lifetime testing } \\
\text { No standardized bending } \\
\text { method } \\
\text { - Integration of electrical } \\
\text { resistance measurement } \\
\text { into bending }\end{array}$ & $\begin{array}{l}\text { - Optimize } \\
\text { film architecture } \\
\text { Optimize ductile film } \\
\text { microstructure to allow } \\
\text { for grain growth } \\
\text { Determine electrical and } \\
\text { mechanical damage } \\
\text { failure criteria } \\
\text { Standardize } \\
\text { bending methods } \\
\text { Understand the in-situ } \\
\text { electrical data }\end{array}$ \\
\hline
\end{tabular}

\section{Material Influences}

With an understanding of how flexible metallic thin film system are evaluated, material design approaches can be applied. In this section, various thin film and material engineering concepts are described that improve the COS, DOS, or cyclic lifetime (as defined as a $20 \%$ increase in relative resistance) of metal films on polymer substrates. Simple but elegant approaches are illustrated that positively (or negatively) influence the electro-mechanical behavior as well as customizing the film architecture or chemistry. These approaches include film thickness, residual stress, and microstructural tailoring and will be discussed in detail.

\subsection{Improving Fracture Resistance of Brittle Films}

The simplest way to alter the COS of a brittle metal film system is to decrease its film thickness. As demonstrated earlier with the use of fragmentation testing, film thickness is directly related to the crack spacing or crack density [41,50,52,54,68,110-112]. A thick film will have a large crack spacing (low crack density) while thin films have a small crack spacing, or large crack density (Figure 3d). The behavior is simply due to the amount of stress a film fragment can carry before reaching the film's fracture stress and is described by the shear lag model (Equation (1)). Along these lines, thinner films will reach higher fracture strains, or COS, compared to the same film with a larger film thickness, regardless of the deposition method. Some good examples in the literature are $[51,52,54,68,83,110]$.

Initially, the role of a film's residual stress was overlooked, and systematic studies were not performed for the same film or film thickness. Now, it is known that with control over the deposition parameters, the residual stress of metals' films can be controlled very well, and even tailored for a specific application. Jörg et al. [83] demonstrated for sputter deposited Mo films with thicknesses between $50 \mathrm{~nm}$ and $500 \mathrm{~nm}$, that a high compressive stress could improve the COS by a factor of three for the same film thickness when strained with uniaxial tension. Additionally, the film residual stresses could be highly tensile to highly compressive with only changing the target power or Ar pressure during magnetron sputtering [31]. The residual stresses were measured with XRD on Si and PI substrates and with a curvature-based method [113]. Further work on tailoring the stresses of Mo films revealed that even under cyclic tensile loading an improved lifetime was observed [102]. The opposite stress tailoring could also be used when the application calls for compressive loading, such as with bending. In this case, a tensile residual stress would be ideal to achieve a high COS and ideally more cycles to failure. Therefore, for a brittle metal film, a thickness of about $10 \mathrm{~nm}$ with a high compressive stress is desired for stretchable applications, and a high tensile stress for compressive bending applications.

For brittle films, the morphology, or shape, the crack takes is mostly dependent on the film microstructure. Cracks in ceramic and oxide films, such as indium tin oxide (ITO), will generally be very long and straight, propagating quickly across the whole sample width due to a lack of crystallinity (amorphous) or very small grains [68,79]. Metal films, however, 
can have straight or wavy (also called zig-zag) cracks that also quickly propagate across the whole sample width. The crack shape is dependent on the grain size and residual stress of the film, which is determined by the deposition method and used parameters. Brittle metals tend to have small grain sizes because they are often very thin when used as adhesion interlayers. A general rule of thumb is that the grain size of a thin film is on the order of the film thickness [114], thus, a $50 \mathrm{~nm}$ thick film would have an average grain size of tens of $\mathrm{nm}$. In most cases, the grain morphology of a thin film is columnar (see Figure $1 \mathrm{a}, \mathrm{b})$. When strained, cracks will propagate along the weakest, or more energetically favorable, paths, which tend to be along the column or grain boundaries. With very small grains, the cracks appear to be straight. The appearance of wavy cracks in single phase and single layer films is due to a larger grain size and the connection of smaller cracks. An example of how the film thickness, microstructure, and crack morphology are related can be found in Figure 8 for three thicknesses of electron beam evaporated Ti films on PI [52]. There is a clear transition in grain size and crack morphology from the $8 \mathrm{~nm}$ film with straight cracks, mixed cracking in the $12 \mathrm{~nm}$ film, to full wavy cracks in the $50 \mathrm{~nm}$ film. In alloy or two-phase films, discussed later, the crack morphology is also related to the grain size, phase distribution, and chemistry. Cracks will still tend to form along column or grain boundaries, but the propagation of the cracks will be more tortuous as the path must go around the different phases to find the more energetically favorable path [115-117]. Highly stressed brittle films, for example, films with a high tensile residual stress, can be pre-cracked. Therefore, additional cracking due to straining will connect pre-existing cracks with newly formed cracks. It is a common misconception to describe wavy or zig-zag cracks as an indication of more ductility in the films when the films illustrate brittle fracture. Ductility can only be measured with a stress-strain curve and not by the crack morphology. The wavy cracks are a direct result of shorter TTCs initiating at low applied strains due to the difference in grain size or phases and connecting at higher strains. The films should still be considered brittle as TTCs form easily when strained or bent. Ductile films, as presented in the next section, fail via different mechanisms than brittle films, thus, the crack morphology for brittle films being straight or wavy is generally unimportant. Rather, as previously discussed, the effective crack lengths of the TTCs are important for the combined electro-mechanical behavior.

\subsection{Microstructural Influences}

Similar to varying the residual stress of a film, the microstructure can also be tailored by changing the deposition parameters. When deposited, some metals will form a bi-modal microstructure with small grains at the interface and large grains as the film thickness increases due to island growth of the film $[83,118]$. With the right deposition parameters and post-deposition heat treatments, the microstructure can be directed to provide the desired mechanical and electrical properties.

Often brittle metal films, such as $\mathrm{Cr}, \mathrm{Mo}$, and Ta, tend to have small grain sizes due to the small thicknesses. Sophisticated deposition conditions, such as oscillating the substrate carrier in front of the target during deposition to create a zig-zag column structure [102], is a way to further alter the microstructure of a thin film. The zig-zag structure was shown to be crack arresting because it can stop long cracks from forming in the plane of the film [102]. Additionally, the zig-zag structure is just as effective under monotonic straining conditions as residual stress tuning for columnar microstructures and even more effective under cyclic tensile straining when the residual stress is also tailored [102]. For the zig-zag microstructure, cracks must continuously change direction to propagate through the film thickness as well as along the plane of the film (across the sample). As such changes in direction need to overcome energetical barriers, the cracks actually stop propagating. Self-reducing printed Ag films can also have a self-arresting structure created from the inherent porous structure of the films [39]. A similar method to arrest cracks is to deposit a film with holes using photolithography methods, also known as micro-patterning. It was shown by the authors in [119] that the presence of holes causes cracks to blunt quickly 
rather than travel across the width of the thermally evaporated $500 \mathrm{~nm}$ thick Ti film on PI. While this improvement is not necessarily due to the film microstructure, the film geometry (blanket vs. with holes) is altered to have crack arresting abilities. However, it should be mentioned that the crack resistance came at the cost of lower conductivity for both the zig-zag and hole structures.
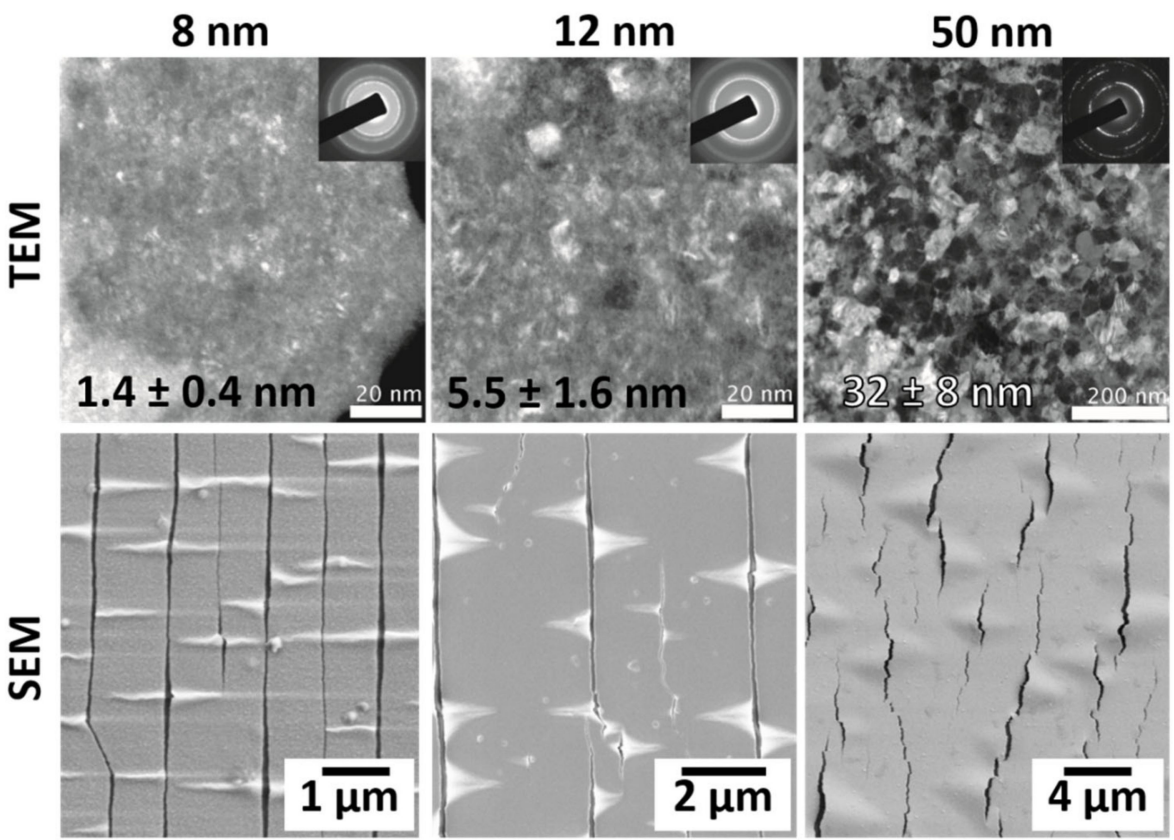

Figure 8. Electron beam evaporated Ti films (8, 12 and $50 \mathrm{~nm}$ thick) on PI have a transition in the crack morphology from long straight cracks to wavy, zig-zag cracks (bottom row) due to the increase in grain size (numbers in images) with increasing film thickness (top row) [52]. TEM images reprinted from Thin Solid Films, Vol. 589, M.J. Cordill and A.A. Taylor, Thickness effect on the fracture and delamination of titanium films, pp. 209-214, (2015) with permission from Elsevier.

Room temperature phase changes can also be used to improve the mechanical performance of metal films on polymer substrates. An example is the martensitic phase transformation in $2 \mu \mathrm{m}$ thick sputter deposited Co films on PI from a metastable $(002)_{\mathrm{fcc}}$ to stable (10-10) hcp and (10-11) hcp [120]. Using in-situ XRD straining experiments with resistance measurements, a reduction of the FCC phase started at less than 1\% applied strain and was observed before TTCs formed at about $6.7 \%$ applied strain. The phase transformation was aided by the formation of necks between applied strains of $2 \%$ and $6.7 \%$. Crack saturation was achieved after $10 \%$ applied strain with the phase transformation ending after applying $8 \%$ strain [120]. In another study, annealing two-phase Co films prior to straining significantly increased the FCC phase. The annealing also led to the higher COS for films between $200 \mathrm{~nm}$ and $2 \mu \mathrm{m}$ thickness, with increased necking deformation before TTC formation for thicker films compared to thinner films [121]. Therefore, room temperature phase transformations are another efficient way to increase the fracture resistance of metal films.

For a ductile film system, $\mathrm{Cu}$ films are often studied because the microstructure can be controlled not only with deposition parameters, but also with post-deposition annealing treatments. As shown by Berger et al. [74], a $200 \mathrm{~nm}$ thick $\mathrm{Cu}$ film on PI initially had an in-plane bi-modal grain size and after annealing for $2 \mathrm{~h}$ at $200{ }^{\circ} \mathrm{C}$ in a vacuum (without removing from deposition chamber), a homogenous grain size of about $2 \mu \mathrm{m}$ was observed. Monotonic straining with in-situ electrical resistance, XRD, and AFM found clear differences between the electro-mechanical behaviors of the annealed and as-deposited films. The maximum stress the films reached was directly related to the film structure with the annealed film having a lower maximum stress. The saturation deformation spacings 
were similar; however, TTCs were observed in the annealed film and not in the as-deposited film. Cracks and necks will form initially in large grains where it is easier for dislocations to glide, especially when twin boundaries are present. The annealed film's electrical response $\left(R / R_{0}\right)$ was always above the as-deposited film. This electrical behavior indicates that the bi-modal microstructure actually is more resistant to damage (less resistance increase) than the annealed film with larger grains and fewer grain boundaries.

When these same and similar $\mathrm{Cu}$ films were subjected to cyclic tensile straining, a more significant difference in electro-mechanical behavior was observed. With cyclic loading, a resistance decrease was found for $\mathrm{Cu}$ films with a bi-modal grain size distribution [122]. This improved resistance has been directly related to grain growth $[87,122]$ and has also been observed in small-grained Au films [86,123] and could be used as a material design element. Ductile metal films with larger grains will not have any grain growth as the structure is already stable. Therefore, deformation and eventual TTCs will more likely form earlier compared to films with a bi-modal grain size distribution or small grains. In general, under monotonic or cyclic tensile loading, small grains in ductile films equal to or thicker than $200 \mathrm{~nm}$ are preferred to large homogenously sized grains. In thinner ductile films, small grains can lead to an immediate fracture [64].

\subsection{Film Architecture and Thickness Ratios}

The previous sections considered single layer films; however, most flexible thin film systems consist of two or more layers. For this discussion, multiple layered films and the layer order will be referred to as the film system's architecture. The type of material (FCC metal-ductile/D, BCC metal-brittle/B), the thickness of the layers, or thickness ratio, and the order of the ductile and brittle layers (layer order) will be examined. Focus will also be on metallic, crystalline thin films, rather than ceramic or glass film systems.

Since the early development of metal films on polymer substrates, brittle metal adhesion layers have been used $[47,48,75,124-126]$. The initial reason behind using the additional layers was to improve adhesion of the ductile conductive layer as poor adhesion was assumed to be the underlying mechanism of crack formation in ductile films [127,128], and for protection due to certain oxidizing processing steps during manufacturing [128]. Since these early works, more has become known about how ductile films on polymer substrates fail mechanically and adhesion does not have as large as an influence as initially believed. Furthermore, with proper deposition parameters, ductile films like $\mathrm{Cu}, \mathrm{Au}, \mathrm{Ag}$, and $\mathrm{Al}$ can have very good adhesion to polymer substrates without using brittle adhesion interlayers $[32,64,65]$. What has been demonstrated with in-situ XRD, AFM, CLSM, and resistance measurements is brittle interlayers $(\mathrm{D} / \mathrm{B})$ and top layers $(\mathrm{B} / \mathrm{D})$ cause the ductile films to fail much sooner than if the brittle layer was not present. This behavior has implications not only for flexible electronics and sensors, but also for nanoscale multilayers $[60,61,129]$ and thin films used in space applications $[65,130,131]$.

Several studies have demonstrated that brittle interlayers cause the early electrical and mechanical failure of ductile films. From experiments and simulations [64], the early failure of normally ductile films with brittle interlayers, such as Cr, Ti, or Mo [64,67,80,122,132,133], has been observed, again independent of the deposition method. In-situ resistance measurements note a deviation from the constant volume approximation well before that of the same film without the interlayer and are dependent on the ductile film thickness [80]. The most telling in-situ experiment is with XRD. Marx et al. [64] demonstrated that the Cu film in $\mathrm{Cu} / \mathrm{Cr}$ bilayers would have a stress-strain curve shape similar to brittle Cr (Figure 9). In the $\mathrm{Cu} / \mathrm{Cr}$ bilayer, the $\mathrm{Cu}$ stress increases to a maximum value then decreases, thus, losing the ability to carry stress because TTC s have formed (Figure 9, open symbols). The single $\mathrm{Cu}$ layers (Figure 9, filled symbols) also achieve a maximum stress, but the stress remains high without decreasing with increasing applied strain, which indicates that the film has not formed TTCs. Finite element simulations, performed to better understand these experiments, found that the thin $10 \mathrm{~nm} \mathrm{Cr}$ layer fractures at about or below 1\% applied strain, creating cracks [64]. The $\mathrm{Cr}$ cracks act as stress concentration points, causing necking 
and TTC formation in the $\mathrm{Cu}$ films at these critical points. More recent work on sputter deposited $\mathrm{Au} / \mathrm{Cr}$ [78] and $\mathrm{Cu} / \mathrm{Mo}$ [133] with additional in-situ resistance measurements have determined that the maximum stresses are related to the fracture stress of the films.

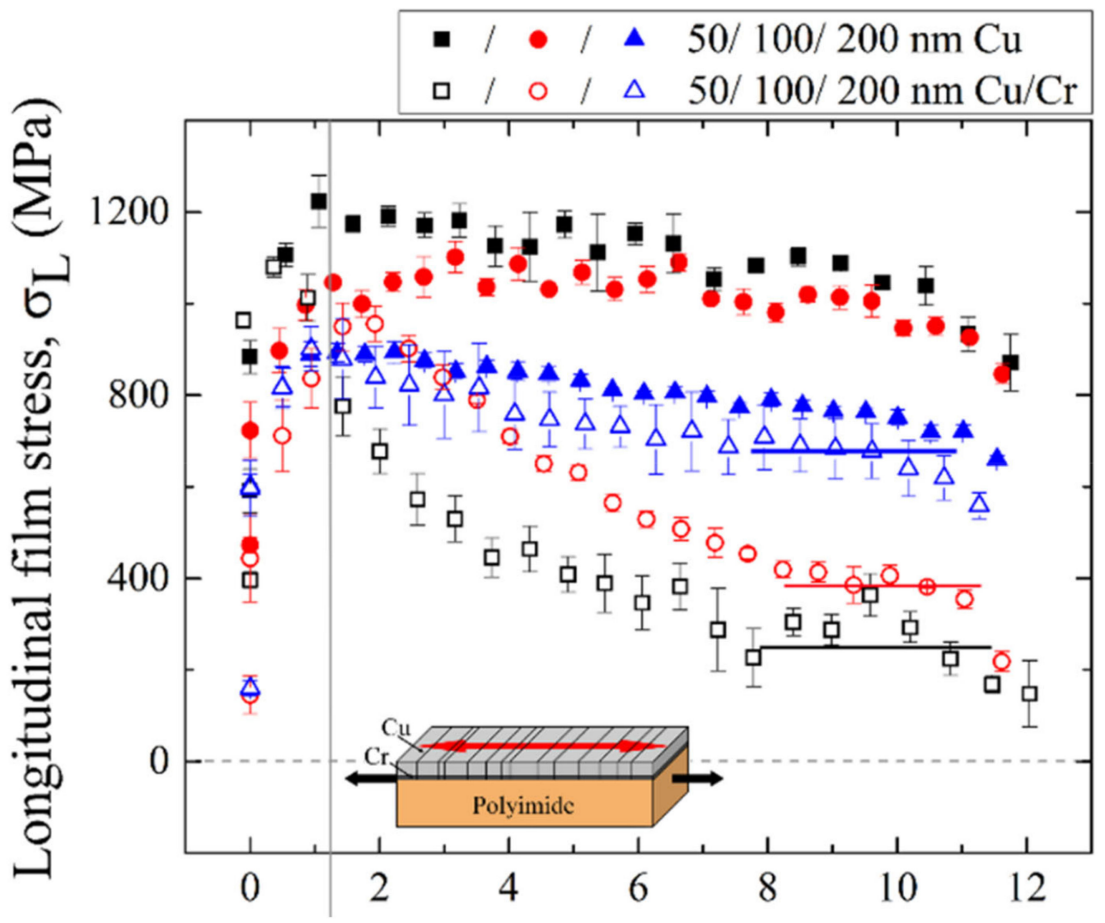

Figure 9. In-situ XRD stress measurements during tensile straining of single layer sputtered $\mathrm{Cu}$ films (50, 100, $200 \mathrm{~nm}$, filled symbols) and $\mathrm{Cu} / \mathrm{Cr}$ bilayers (10 nm Cr interlayers, same $\mathrm{Cu}$ thicknesses, open symbols) illustrate that when brittle interlayers are used, the $\mathrm{Cu}$ film stresses decrease after reaching a maximum stress due to TTC formation. The single $\mathrm{Cu}$ layers continue to have high stresses with further applied strain because TTCs do not form. Figure from [64]. Reprinted from Acta Materilia, Vol. 89, V.M Marx, F. Toth, A. Wiesinger, J. Berger, C. Kirchlechner, M.J. Cordill, F.D. Fischer, F.G. Rammerstorfer, G. Dehm, The influence of a brittle $\mathrm{Cr}$ interlayer on the deformation behavior of thin Cu films on flexible substrates: Experiment and model, p. 278-289, (2015) with permission from Elsevier (CC by 4.0).

More experiments were performed with sputter deposited $\mathrm{Cu}$ and Mo bilayers with different film thickness ratios and with a slightly thicker Mo film. With the thicker Mo film, not only could the $\mathrm{Cu}$ stress be measured, but also the stress of the Mo layers [133]. With the mechanical information of both layers, it was found that the thicker Cu layers can actually improve the apparent fracture toughness, $K_{I c}$, of the Mo layer, up to a thickness ratio of 5:1 (Cu:Mo). Similar research on sputtered Al/Mo bilayers strained biaxially has also demonstrated an improvement in the fracture stress of the Mo interlayer with thicker $\mathrm{Al}$ layers [118,132]. When the bilayer is reversed to $\mathrm{Mo} / \mathrm{Al}$, the opposite trend is observed, and thinner Al films improve the fracture strain of the Mo film [118].

It should be noted that the thickness ratio between the ductile layer and brittle layer can be used as a design criterion, but it is not universal and is different for every material system. Under monotonic tensile straining in order to suppress TTC formation in the ductile layer, a thickness ratio of 20:1 is best for the $\mathrm{Cu} / \mathrm{Cr}$ on PI [64], and for $\mathrm{Al} / \mathrm{Mo}$ on PI a thickness ratio of 10:1 works well [80]. However, for Au/Cr also on PI, 5:1 is not enough to hinder TTC formation, especially when the films are $50 \mathrm{~nm}$ and $10 \mathrm{~nm}$, respectively [67,78]. The Inconel-Ag on Teflon [65] with a thickness ratio of 1:5 is also not sufficient with thicknesses of $30 \mathrm{~nm}$ and $150 \mathrm{~nm}(\mathrm{Ag})$ and the reversed layer order (brittle layer on top). Further studies, especially with in-situ XRD, are necessary. XRD is the only technique that can probe multiple material behaviors simultaneously, and thus is the only method suitable for bilayer and multilayer behavior to be properly investigated. These 
initial results strongly indicate that the film architecture matters, and once understood, could be exploited as a powerful material design concept.

\subsection{Alloying}

Thin film deposition techniques allow for a variety of metal alloys to be achieved, even if they are unstable in the bulk form. In the research stage, co-sputtering with multiple targets permits for a wide range of chemistries and structures to be created and evaluated as thin films. Alloying is an excellent technique to increase fracture resistance in brittle metals films $[115,116,134]$ and in ductile metal films $[117,135,136]$. One of the most alloyed brittle metal films on polymers found in literature is Mo. Mo has successfully been alloyed with $\mathrm{Re}, \mathrm{Cu}, \mathrm{Ag}, \mathrm{Nb}, \mathrm{Ta}$, and $\mathrm{Al}[115,116,134]$. For most alloy combinations, as the $\mathrm{Mo}$ content decreased, an improvement of the COS was observed along with a change in the crack morphology from long straight cracks to shorter zig-zag cracks. Crack morphology has already been discussed (Section 4.1); therefore, the effects on the COS and electrical resistance will be focused on here. With the different alloy compositions and the improved COS values, the change in electrical resistance with decreasing Mo content rarely follows the same trend (Figure 10). Alloying produces additional electron scattering sources in a pure metal crystal and reaches a maximum at $50 \%$ when there is total miscibility. Additionally, residual stresses will also play a role (Section 4.1). In order to have a more robust and longer lasting flexible electronic device or sensor, the electrical resistance must also be considered as a design criterion. In Figure 10, for various Mo-based alloys the resistivity as a function of the measured COS is shown for $50 \mathrm{~nm}$ and $500 \mathrm{~nm}$ thick films. For $50 \mathrm{~nm}$ thick films (Figure 10a), the Mo-Al alloys have an improved COS, but also have very high resistivities which make them inadequate for flexible electronic applications. On the other hand, Mo-Ta alloys have low resistivities and the highest COS values. For thicker Mo-based alloy films, the $\mathrm{Mo}-\mathrm{Al}$ alloys achieve a higher $\mathrm{COS}$ with an adequate increased resistivity (Figure 10b). In such a graph as in Figure 10, the goal is to go as far right in the COS values while keeping the resistivity as low as possible.
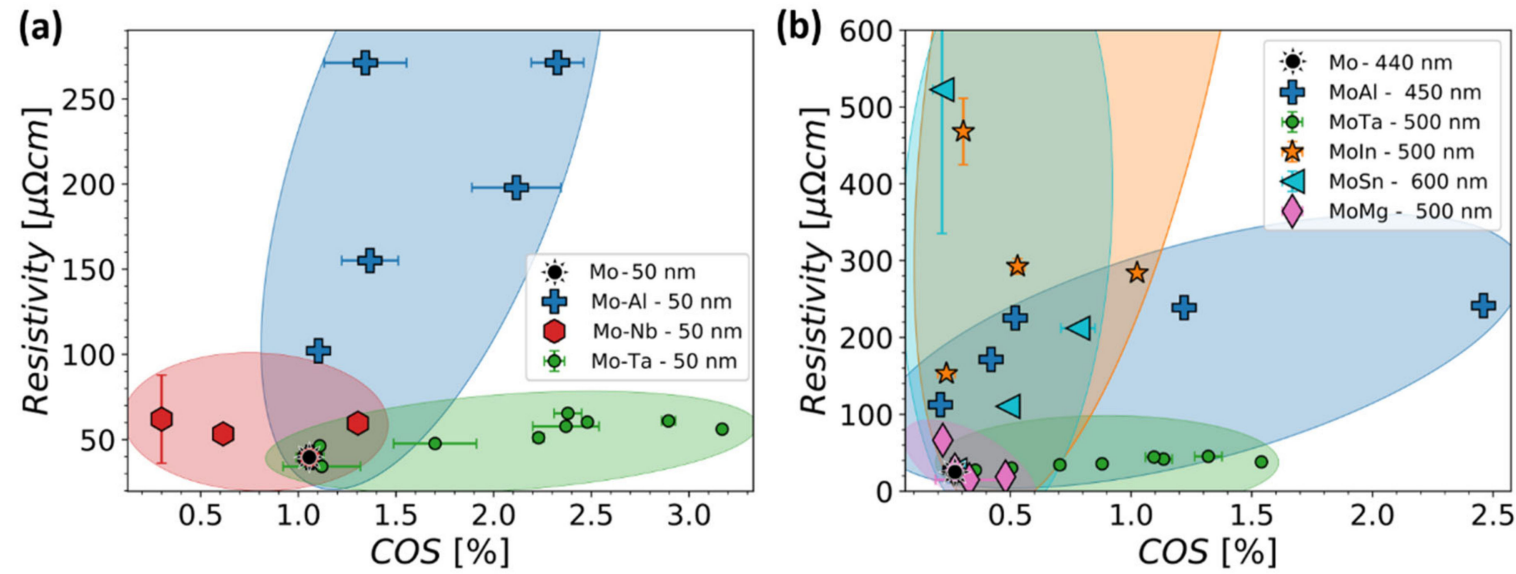

Figure 10. Map of electrical resistivity versus COS for (a) $50 \mathrm{~nm}$ and (b) $500 \mathrm{~nm}$ thick Mo-based alloy film systems with different chemical compositions. The highlighted areas act as guides for the eye to collect similar alloy systems and have no mathematical or statistical meaning.

The co-sputter deposited Mo-Ta alloy has been used as an interlayer with conductive $\mathrm{Al}$ on PI and tested under monotonic tensile straining and bending [108]. After stress tailoring the interlayer alloy, the $\mathrm{Al} / \mathrm{Mo}$-Ta bilayers performed similarly under uniaxial tensile straining with a $1 \%$ improvement in COS compared to the $\mathrm{Al} / \mathrm{Mo}$ bilayers with the same thickness ratios (D:B). However, under mixed compressive tensile bending using a bending strain of $1.3 \%$, the $\mathrm{Al} / \mathrm{Mo}-\mathrm{Ta}$ bilayers vastly outperformed the same $\mathrm{Al} / \mathrm{Mo}$ bilayers. No damage or cracks were observed after 50,000 cycles in the Al/Mo-Ta bilayers, while the $\mathrm{Al} / \mathrm{Mo}$ bilayers were completely damaged [108]. However, after 100 cycles 
using a higher bending strain of 3.1\%, cracks formed in the Al/Mo-Ta bilayers [108]. This study illustrates that the material behavior can be applied to the right application, in this case bending of $1.3 \%$ or lower produces a robust, nearly unbreakable, and electrically conductive film system. Table 2 summarizes the design concepts introduced with their benefits, limitations, and possible solutions for future reference.

Table 2. Summary of benefits, limitations, and possible solutions for fabricating robust brittle or ductile metal films on polymer substrates.

\begin{tabular}{|c|c|c|c|c|}
\hline Material & $\begin{array}{l}\text { Deposition } \\
\text { Method }\end{array}$ & Benefit(s) & Limitation(s) & Solution(s) \\
\hline \multirow[t]{2}{*}{ Brittle Film } & Sputtering & $\begin{array}{l}\text { - Can improve adhesion } \\
\text { to polymer substrate } \\
\text { As top layer can } \\
\text { improve fracture } \\
\text { strength of } \\
\text { ductile layer }\end{array}$ & 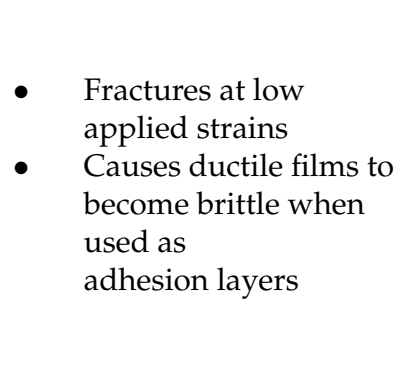 & $\begin{array}{l}\text { Use thick ductile films } \\
\text { with a thickness ratio } \\
\text { of at least 1:5 } \\
\text { (brittle:ductile) } \\
\text { - } \quad \text { Avoid use if possible } \\
\text { - } \\
\text { Alloy with more } \\
\text { ductile metal } \\
\text { - } \quad \text { Create crack arresting } \\
\text { microstructure } \\
\text { - } \\
\text { Increase residual stress }\end{array}$ \\
\hline & Evaporation & $\begin{array}{l}\text { - Can improve adhesion } \\
\text { to polymer substrate }\end{array}$ & $\begin{array}{l}\text { Interface may not be } \\
\text { thermally stable and } \\
\text { delaminate } \\
\text { Deposition of } \\
\text { refractory metals may } \\
\text { thermally overload } \\
\text { polymer substrates }\end{array}$ & $\begin{array}{l}\text { - } \quad \text { Avoid use if possible } \\
\text { Alloy with more } \\
\text { ductile metal }\end{array}$ \\
\hline Ductile Film & Evaporation & $\begin{array}{l}\text { - Conductive for } \\
\text { electrical applications } \\
\text { - Can have a thermally } \\
\text { stable interface }\end{array}$ & $\begin{array}{l}\text { - When thin }(\leq 100 \mathrm{~nm}) \\
\text { can easily form cracks } \\
\text { May require brittle } \\
\text { adhesion layers }\end{array}$ & $\begin{array}{l}\text { - } \quad \text { Adapt deposition } \\
\text { parameters to have } \\
\text { larger grains or to alter } \\
\text { interface structure } \\
\text { Use very thin } \\
\text { ( } \leq 10 \text { nm) brittle layers } \\
\text { to improve adhesion }\end{array}$ \\
\hline
\end{tabular}

\section{Summary}

As presented, thin metal films can be designed to have ideal electrical and mechanical behaviors for flexible and stretchable electronics. With a clear understanding of the various thin film deposition methods and the physics behind film growth, advanced thin films with superior mechanical and functional behaviors can be created. Additionally, fabrication scalability is a concern that material design can easily address. As demonstrated for the $\mathrm{Al} / \mathrm{Mo}$-Ta system, when we know the material system's limitations, then an application can be selected that is suitable. When the material design aspect has reached its limits, then additional device engineering concepts (i.e., meanders, wrinkling, free-standing bridges, etc.) should be exploited. It is beneficial to first utilize the materials' design before more complex device engineering in order to use the same methods and large-scale deposition infrastructure that is currently available for the industry. The utilization of both material design and device engineering concepts will lead to synergetic affects, reduced complexity, reduced production costs, and an increase in the lifetime of a device. Changes to the available infrastructure is costly and not sustainable. The presently available understanding of thin film deposition processes, the available (in-situ) testing methods, and the gained insight into electro-mechanical degradation behavior enable the tailoring of metallic thin films for tomorrow's flexible electronic applications. Both the robustness of the described 
approaches on a large-scale and their optimization require the continued combined efforts of academia and industry.

Author Contributions: Conceptualization, M.J.C. and C.M., data curation, M.J.C., P.K. and C.M.; writing—original draft preparation, M.J.C., P.K. and C.M.; writing-review and editing, M.J.C., P.K. and C.M. All authors have read and agreed to the published version of the manuscript.

Funding: This research received no external funding.

Institutional Review Board Statement: Not applicable.

Informed Consent Statement: Not applicable.

Data Availability Statement: Any new data presented is available upon reasonable request by the authors.

Acknowledgments: Several micrographs were provided by colleagues at the Erich Schmid Institute for Materials Science (ESI), Austrian Academy of Sciences and the Department of Materials Science, Montanuniversität Leoben (MUL). We would like to acknowledge their contributions to the manuscript: B. Putz (ESI/MUL), C. Gammer (ESI), B. Völker (ESI), and O. Glushko (MUL).

Conflicts of Interest: The authors declare no conflict of interest.

\section{References}

1. Rogers, J.A.; Someya, T.; Huang, Y. Materials and Mechanics for Stretchable Electronics. Science 2010, 327, 1603-1607. [CrossRef] [PubMed]

2. Schubert, M.B.; Werner, J.H. Flexible solar cells for clothing. Mater. Today 2006, 9, 42-50. [CrossRef]

3. Lee, S.; Shin, J.; Jang, J. Top Interface Engineering of Flexible Oxide Thin-Film Transistors by Splitting Active Layer. Adv. Funct. Mater. 2017, 27, 1604921. [CrossRef]

4. Kaltenbrunner, M.; Sekitani, T.; Reeder, J.; Yokota, T.; Kuribara, K.; Tokuhara, T.; Drack, M.; Schwödiauer, R.; Graz, I.; BauerGogonea, S.; et al. An ultra-lightweight design for imperceptible plastic electronics. Nature 2013, 499, 458-463. [CrossRef]

5. Lacour, S.P.; Wagner, S.; Narayan, R.J.; Li, T.; Suo, Z. Stiff subcircuit islands of diamondlike carbon for stretchable electronics. J. Appl. Phys. 2006, 100, 014913. [CrossRef]

6. Wagner, S.; Bauer, S. Materials for stretchable electronics. MRS Bull. 2012, 37, 207-213. [CrossRef]

7. McBride, J.W.; Lam, L. A review of conducting polymers in electrical contact applications. In Proceedings of the International Conference of Polymeric Materials in Power Engineering (ICPMPE), Singapore, 3-6 December 2007; p. 9.

8. Kraft, U.; Molina-Lopez, F.; Son, D.; Bao, Z.; Murmann, B. Ink Development and Printing of Conducting Polymers for Intrinsically Stretchable Interconnects and Circuits. Adv. Electron. Mater. 2020, 6, 1900681. [CrossRef]

9. Konuma, M. Film Deposition by Plasma Techniques, 1st ed.; Springer: Berlin/Heidelberg, Germany, 1992; ISBN 978-3-642-84511-6.

10. Mattox, D.M. Handbook of Physical Vapor Deposition (PVD) Processing, 2nd ed.; Elsevier: Oxford, UK, 2010.

11. Window, B. Issues in magnetron sputtering of hard coatings. Surf. Coat. Technol. 1996, 81, 92-98. [CrossRef]

12. Bräuer, G.; Szyszka, B.; Vergöhl, M.; Bandorf, R. Magnetron sputtering-Milestones of 30 years. Vacuum 2010, 84, 1354-1359. [CrossRef]

13. Sproul, W.D.; Christie, D.J.; Carter, D.C. Control of reactive sputtering processes. Thin Solid Films 2005, 491, 1-17. [CrossRef]

14. Arnell, R.D.; Kelly, P.J. Recent advances in magnetron sputtering. Surf. Coat. Technol. 1999, 112, 170-176. [CrossRef]

15. Sellers, J. Asymmetric bipolar pulsed DC: The enabling technology for reactive PVD. Surf. Coat. Technol. 1998, 98, 1245-1250. [CrossRef]

16. Petrov, I.; Barna, P.B.; Hultman, L.; Greene, J.E. Microstructural evolution during film growth. J. Vac. Sci. Technol. A 2003, 21, S117-S128. [CrossRef]

17. Barbee, T.W.; Holmes, W.H.; Keith, D.L.; Pyzyna, M.K.; Ilonca, G. Synthesis of amorphous niobium-nickel alloys by vapor quenching. Thin Solid Films 1977, 45, 591-599. [CrossRef]

18. Hora, J.; Hall, C.; Evans, D.; Charrault, E. Inorganic Thin Film Deposition and Application on Organic Polymer Substrates. Adv. Eng. Mater. 2018, 20, 1700868. [CrossRef]

19. Rausch, M.; Pavlovič, M.; Kreiml, P.; Cordill, M.J.; Winkler, J.; Mitterer, C. Sputter deposition of Mo-based multicomponent thin films from rotatable targets: Experiment and simulation. Appl. Surf. Sci. 2018, 455, 1029-1036. [CrossRef]

20. Greene, J.E. Tracing the recorded history of thin-film sputter deposition: From the 1800s to 2017. J. Vac. Sci. Technol. A 2017, 35, 05C204. [CrossRef]

21. Movchan, B.A.; Demchishin, A. Investigates of the structure and properties of thick vaccum-deposited films of nickel, titanium, tungsten, alumina, and zirconium dioxide. Fiz. Metal. Metalloved. 1969, 28, 653-660.

22. Anders, A. A structure zone diagram including plasma-based deposition and ion etching. Thin Solid Films 2010, 518, 4087-4090. [CrossRef] 
23. Rausch, M.; Sabag, A.; Pichler, K.-H.; Gruber, G.C.; Köstenbauer, J.; Köstenbauer, H.; Kreiml, P.; Cordill, M.J.; Winkler, J.; Mitterer, C. The sputter performance of an industrial-scale planar Mo-target over its lifetime: Target erosion and fi lm properties. Surf. Coat. Technol. 2020, 381, 125174. [CrossRef]

24. Kukla, R. Magnetron sputtering on large scale substrates: An overview on the state of the art. Surf. Coat. Technol. 1997, 93, 1-6. [CrossRef]

25. De Gryse, R.; Haemers, J.; Leroy, W.P.; Depla, D. Thirty years of rotatable magnetrons. Thin Solid Films 2012, 520, 5833-5845. [CrossRef]

26. Souk, J.; Morozumi, S.; Luo, F.; Bita, I. (Eds.) Flat Panel Display Manufacturing; John Wiley \& Sons, Ltd.: Hoboken, NJ, USA, 2018.

27. Lorenz, R.; O'Sullivan, M.; Sprenger, D.; Lang, B.; Köstenbauer, H.; Winkler, J.; Mitterer, C. Oxidation and wet-etching behavior of MoAlTi thin films deposited by sputtering from a rotatable MoAlTi compound target. J. Vac. Sci. Technol. B 2019, $37,021202$. [CrossRef]

28. Jörg, T.; Hofer, A.M.; Köstenbauer, H.; Winkler, J.; Mitterer, C. Oxidation and wet etching behavior of sputtered Mo-Ti-Al films J. Vac. Sci. Technol. A 2018, 36, 021513. [CrossRef]

29. Choi, M.-C.; Kim, Y.; Ha, C.-S. Polymers for flexible displays: From material selection to device applications. Prog. Polym. Sci. 2008, 33, 581-630. [CrossRef]

30. Tsukada, T.; Hosokawa, N. Adhesion of Copper Films on Abs Polymers Deposited in an Internal Magnet Magnetron Sputtering System. J. Vac. Sci. Technol. 1979, 16, 348-351. [CrossRef]

31. Jörg, T.; Cordill, M.J.; Franz, R.; Glushko, O.; Winkler, J.; Mitterer, C. The electro-mechanical behavior of sputter-deposited Mo thin films on flexible substrates. Thin Solid Films 2016, 606, 45-50. [CrossRef]

32. Putz, B.; Milassin, G.; Butenko, Y.; Völker, B.; Gammer, C.; Semprimoschnig, C.; Cordill, M.J. Combined TEM and XPS studies of metal-polymer interfaces for space applications. Surf. Coat. Technol. 2017, 332, 368-375. [CrossRef]

33. Daniel, R.; Martinschitz, K.J.; Keckes, J.; Mitterer, C. The origin of stresses in magnetron-sputtered thin films with zone T structures. Acta Mater. 2010, 58, 2621-2633. [CrossRef]

34. Jin, H.; Lu, W.-Y.; Cordill, M.J.; Schmidegg, K. In situ Study of Cracking and Buckling of Chromium Films on PET Substrates Exp. Mech. 2011, 51, 219-227. [CrossRef]

35. Swartwout, R.; Hoerantner, M.T.; Bulović, V. Scalable Deposition Methods for Large-area Production of Perovskite Thin Films. Energy Environ. Mater. 2019, 2, 119-145. [CrossRef]

36. Park, J.; Shin, K.; Lee, C. Roll-to-Roll Coating Technology and Its Applications: A Review. Int. J. Precis. Eng. Manuf. 2016, 17, 537-550. [CrossRef]

37. Tekin, E.; Smith, P.J.; Schubert, U.S. Inkjet printing as a deposition and patterning tool for polymers and inorganic particles. Soft Matter 2007, 4, 703-713. [CrossRef] [PubMed]

38. Samusjew, A.; Lassnig, A.; Cordill, M.J.; Krawczyk, K.K.; Griesser, T. Inkjet Printed Wiring Boards with Vertical Interconnect Access on Flexible, Fully Compostable Cellulose Substrates. Adv. Mater. Technol. 2017, 3, 1700250. [CrossRef]

39. Krawczyk, K.K.; Groten, J.; Glushko, O.; Krivec, M.; Frühwirth, M.; Schulz, G.; Wolf, C.; Hartmann, D.; Moser, M.; Cordill, M.J.; et al. Self-Reducing Silver Ink on Polyurethane Elastomers for the Manufacture of Thin and Highly Stretchable Electrical Circuits Chem. Mater. 2021, 33, 2742-2755. [CrossRef]

40. Perelaer, J.; de Gans, B.-J.; Schubert, U.S. Ink-jet Printing and Microwave Sintering of Conductive Silver Tracks. Adv. Mater. 2006, 18, 2101-2104. [CrossRef]

41. Agrawal, D.C.; Raj, R. Measurement of the ultimate shear strength of a metal-ceramic interface. Acta Metall. 1989, 37, 1265-1270. [CrossRef]

42. Kelly, A.; Tyson, W.R. Tensile properties of fibre-reinforced metals: Copper/tungsten and copper/molybdenum. J. Mech. Phys. Solids 1965, 13, 329-350. [CrossRef]

43. Jobin, V.C.; Raj, R.; Phoenix, S.L. Rate effects in metal-ceramic interface sliding from the periodic film cracking technique Acta Metall. Mater. 1992, 40, 2269-2280. [CrossRef]

44. Spaepen, F. Interfaces and stresses in thin films. Acta Mater. 2000, 48, 31-42. [CrossRef]

45. Li, T.; Huang, Z.; Suo, Z.; Lacour, S.P.; Wagner, S. Stretchability of thin metal films on elastomer substrates. Appl. Phys. Lett. 2004, 85, 3435-3437. [CrossRef]

46. Lacour, S.P.; Tsay, C.; Wagner, S. An elastically stretchable TFT circuit. IEEE Electron Device Lett. 2004, 25, 792-794. [CrossRef]

47. Ho, P.S.; Faupel, F. Adhesion and deformation study of metal/polymer structures by a stretch deformation method. Appl. Phys. Lett. 1988, 53, 1602-1604. [CrossRef]

48. Faupel, F.; Yang, C.H.; Chen, S.T.; Ho, P.S. Adhesion and deformation of metal/polyimide layered structures. J. Appl. Phys. 1989, 65, 1911-1917. [CrossRef]

49. Taylor, A.A.; Cordill, M.J.; Dehm, G. On the limits of the interfacial yield model for fragmentation testing of brittle films on polymer substrates. Philos. Mag. 2012, 92,3363-3380. [CrossRef]

50. Taylor, A.A.; Edlmayr, V.; Cordill, M.J.; Dehm, G. The effect of film thickness variations in periodic cracking: Analysis and experiments. Surf. Coat. Technol. 2011, 206, 1830-1836. [CrossRef]

51. Cordill, M.J.; Taylor, A.A.; Berger, J.; Schmidegg, K.; Dehm, G. Robust mechanical performance of chromium-coated polyethylene terephthalate over a broad range of conditions. Philos. Mag. 2012, 92, 3346-3362. [CrossRef] 
52. Cordill, M.J.; Taylor, A.A. Thickness effect on the fracture and delamination of titanium films. Thin Solid Films 2015, 589, 209-214. [CrossRef]

53. Toth, F.; Rammerstorfer, F.G.; Cordill, M.J.; Fischer, F.D. Detailed modelling of delamination buckling of thin films under global tension. Acta Mater. 2013, 61, 2425-2433. [CrossRef]

54. Cordill, M.J.; Taylor, A.; Schalko, J.; Dehm, G. Fracture and delamination of chromium thin films on polymer substrates. Metall. Mater. Trans. A 2010, 41, 870-875. [CrossRef]

55. Cordill, M.J.; Fischer, F.D.; Rammerstorfer, F.G.; Dehm, G. Adhesion energies of Cr thin films on polyimide determined from buckling: Experiment and model. Acta Mater. 2010, 58, 5520-5531. [CrossRef]

56. Frank, S.; Gruber, P.; Handge, U.A.; Spolenak, R. In situ studies on the cohesive properties of $\alpha$ - And $\beta$-Ta layers on polyimide substrates. Acta Mater. 2011, 59, 5881-5892. [CrossRef]

57. Frank, S.; Handge, U.A.; Olliges, S.; Spolenak, R. The relationship between thin film fragmentation and buckle formation: Synchrotron-based in situ studies and two-dimensional stress analysis. Acta Mater. 2009, 57, 1442-1453. [CrossRef]

58. Taylor, A.A.; Cordill, M.J.; Bowles, L.; Schalko, J.; Dehm, G. An elevated temperature study of a Ti adhesion layer on polyimide. Thin Solid Films 2013, 531, 354-361. [CrossRef]

59. Leterrier, Y.; Mottet, A.; Bouquet, N.; Gilliéron, D.; Dumont, P.; Pinyol, A.; Lalande, L.; Waller, J.H.; Månson, J.-A.E. Mechanical integrity of thin inorganic coatings on polymer substrates under quasi-static, thermal and fatigue loadings. Thin Solid Films 2010, 519, 1729-1737. [CrossRef]

60. Cordill, M.J.; Kleinbichler, A.; Völker, B.; Kraker, P.; Economy, D.R.; Többens, D.; Kirchlechner, C.; Kennedy, M.S. In-situ observations of the fracture and adhesion of $\mathrm{Cu} / \mathrm{Nb}$ multilayers on polyimide substrates. Mater. Sci. Eng. A 2018, 735, 456-462. [CrossRef]

61. Polyakov, M.N.; Lohmiller, J.; Gruber, P.A.; Hodge, A.M. Load Sharing Phenomena in Nanoscale Cu/Nb Multilayers. Adv. Eng. Mater. 2015, 17, 810-814. [CrossRef]

62. Wu, K.; Zhang, J.Y.; Li, J.; Wang, Y.Q.; Liu, G.; Sun, J. Length-scale-dependent cracking and buckling behaviors of nanostructured $\mathrm{Cu} / \mathrm{Cr}$ multilayer films on compliant substrates. Acta Mater. 2015, 100, 344-358. [CrossRef]

63. Gruber, P.A.; Arzt, E.; Spolenak, R. Brittle-to-ductile transition in ultrathin Ta/Cu film systems. J. Mater. Res. 2009, 24, 1906-1918. [CrossRef]

64. Marx, V.M.; Toth, F.; Wiesinger, A.; Berger, J.; Kirchlechner, C.; Cordill, M.J.; Fischer, F.D.; Rammerstorfer, F.G.; Dehm, G. The influence of a brittle $\mathrm{Cr}$ interlayer on the deformation behavior of thin $\mathrm{Cu}$ films on flexible substrates: Experiment and model. Acta Mater. 2015, 89, 278-289. [CrossRef]

65. Putz, B.; May-Miller, C.; Matl, V.; Völker, B.; Többens, D.M.; Semprimoschnig, C.; Cordill, M.J. Two-stage cracking of metallic bi-layers on polymer substrates under tension. Scr. Mater. 2018, 145, 5-8. [CrossRef]

66. Glushko, O.; Klug, A.; List-Kratochvil, E.J.W.; Cordill, M.J. Relationship between mechanical damage and electrical degradation in polymer-supported metal films subjected to cyclic loading. Mater. Sci. Eng. A 2016, 662, 157-161. [CrossRef]

67. Putz, B.; Schoeppner, R.L.; Glushko, O.; Bahr, D.F.; Cordill, M.J. Improved electro-mechanical performance of gold films on polyimide without adhesion layers. Scr. Mater. 2015, 102, 23-26. [CrossRef] [PubMed]

68. Leterrier, Y. Durability of nanosized oxygen-barrier coatings on polymers. Prog. Mater. Sci. 2003, 48, 1-55. [CrossRef]

69. Cordill, M.J.; Paulitsch, M.; Katsarelis, C.; Putz, B.; Lassnig, A.; Kennedy, M.S. Influence of interlayers onthe intefacial behavior of Ag films on polymer substrates. Thin Solid Films 2022, 742, 139051. [CrossRef]

70. Cordill, M.J.; Marx, V.M. Fragmentation testing for ductile thin films on polymer substrates. Philos. Mag. Lett. 2013, 93, 618-624. [CrossRef]

71. Cordill, M.J.; Marx, V.M. In-situ tensile straining of metal films on polymer substrates under an AFM. MRS Online Proc. Libr. 2013, 1527, 607. [CrossRef]

72. Preiß, E.I.; Merle, B.; Göken, M. Understanding the extremely low fracture toughness of freestanding gold thin films by in-situ bulge testing in an AFM. Mater. Sci. Eng. A 2017, 691, 218-225. [CrossRef]

73. Cordill, M.J.; Glushko, O.; Kreith, J.; Marx, V.M.; Kirchlechner, C. Measuring electro-mechanical properties of thin films on polymer substrates. Microelectron. Eng. 2015, 137, 96-100. [CrossRef]

74. Berger, J.; Glushko, O.; Marx, V.M.; Kirchlechner, C.; Cordill, M.J. Effect of microstructure on the electro-mechanical behavior of $\mathrm{Cu}$ films on polyimide. JOM 2016, 68, 1640-1646. [CrossRef]

75. Lu, N.; Wang, X.; Suo, Z.; Vlassak, J.J. Metal films on polymer substrates stretched beyond 50\%. Appl. Phys. Lett. 2007, 91, 221909. [CrossRef]

76. Glushko, O.; Cordill, M.J. Electrical Resistance of Metal Films on Polymer Substrates under Tension. Exp. Tech. 2016, 40, 303-310. [CrossRef]

77. Lu, N.; Wang, X.; Suo, Z.; Vlassak, J. Failure by simultaneous grain growth, strain localization, and interface debonding in metal films on polymer substrates. J. Mater. Res. 2009, 24, 379-385. [CrossRef]

78. Putz, B.; Glushko, O.; Marx, V.M.; Kirchlechner, C.; Toebbens, D.; Cordill, M.J. Electro-mechanical performance of thin gold films on polyimide. MRS Adv. 2016, 1,773-778. [CrossRef]

79. Cordill, M.J.; Glushko, O.; Putz, B. Electro-Mechanical Testing of Conductive Materials Used in Flexible Electronics. Front. Mater. 2016, 3, 11. [CrossRef] 
80. Kreiml, P.; Rausch, M.; Terziyska, V.L.; Köstenbauer, H.; Winkler, J.; Mitterer, C.; Cordill, M.J. Electro-mechanical behavior of $\mathrm{Al} /$ Mo bilayers studied with in situ straining methods. Thin Solid Films 2018, 665, 131-136. [CrossRef]

81. Schlich, F.F.; Wyss, A.; Galinski, H.; Spolenak, R. Cohesive and adhesive properties of ultrathin amorphous and crystalline Ge2Sb2Te5 films on polyimide substrates. Acta Mater. 2017, 126, 264-271. [CrossRef]

82. Schlich, F.F.; Spolenak, R. Size- and phase-dependent mechanical properties of ultrathin Si films on polyimide substrates. Acta Mater. 2016, 110, 122-130. [CrossRef]

83. Jörg, T.; Cordill, M.J.; Franz, R.; Kirchlechner, C.; Többens, D.M.; Winkler, J.; Mitterer, C. Thickness dependence of the electromechanical response of sputter-deposited Mo thin films on polyimide: Insights from in-situ sychrotron diffraction tensile tests. Mater. Sci. Eng. A 2017, 697, 17-23. [CrossRef]

84. Glushko, O.; Kraker, P.; Cordill, M.J. Explicit relationship between electrical and topological degradation of polymer-supported metal films subjected to mechanical loading. Appl. Phys. Lett. 2017, 110, 191904. [CrossRef]

85. Glushko, O.; Putz, B.; Cordill, M.J. Determining effective crack lengths from electrical measurements in polymer-supported thin films. Thin Solid Films 2020, 699, 137906. [CrossRef]

86. Glushko, O.; Klug, A.; List-Kratochvil, E.J.W.; Cordill, M.J. Monotonic and cyclic mechanical reliability of metallization lines on polymer substrates. J. Mater. Res. 2017, 32, 1760-1769. [CrossRef]

87. Glushko, O.; Cordill, M.J. Electrical Resistance Decrease Due to Grain Coarsening Under Cyclic Deformation. JOM 2014, 66, 598-601. [CrossRef]

88. Schwaiger, R.; Dehm, G.; Kraft, O. Cyclic deformation of polycrystalline Cu films. Philos. Mag. 2003, 83, 693-710. [CrossRef]

89. Kraft, O.; Wellner, P.; Hommel, M.; Schwaiger, R.; Arzt, E. Fatigue behavior of polycrystalline thin copper films. Z. Fuer Met. Res. Adv. Tech. 2002, 93, 392-400. [CrossRef]

90. Kraft, O.; Schwaiger, R.; Wellner, P. Fatigue in thin films: Lifetime and damage formation. Mater. Sci. Eng. A 2001, 319-321, 919-923. [CrossRef]

91. Zhang, G.P.; Schwaiger, R.; Volkert, C.A.; Kraft, O. Effect of film thickness and grain size on fatigue-induced dislocation structures in $\mathrm{Cu}$ thin films. Philos. Mag. Lett. 2003, 83, 477-483. [CrossRef]

92. Sun, X.J.; Wang, C.C.; Zhang, J.; Liu, G.; Zhang, G.J.P.; Ding, X.D.; Zhang, G.J.P.; Sun, J. Thickness dependent fatigue life at microcrack nucleation for metal thin films on flexible substrates. J. Phys. D Appl. Phys. 2008, 41, 195404. [CrossRef]

93. Trinks, C.; Volkert, C.A. Transition from dislocation glide to creep controlled damage in fatigued thin Cu films. J. Appl. Phys. 2013, 114, 093510. [CrossRef]

94. Kim, B.J.; Shin, H.A.S.; Lee, J.H.; Yan, T.Y.; Haas, T.; Gruber, P.; Chou, I.S.; Kraft, O.; Joo, Y.C. Effect of film thickness on the stretchability and fatigue resistance of $\mathrm{Cu}$ films on polymer substrates. J. Mater. Res. 2014, 29, 2827-2834. [CrossRef]

95. Kim, B.-J.; Haas, T.; Friederich, A.; Lee, J.-H.; Nam, D.-H.; Binder, J.R.; Bauer, W.; Choi, I.-S.; Joo, Y.-C.; Gruber, P.A.; et al Improving mechanical fatigue resistance by optimizing the nanoporous structure of inkjet-printed Ag electrodes for flexible devices. Nanotechnology 2014, 25, 125706. [CrossRef] [PubMed]

96. Sim, G.-D.; Lee, Y.-S.; Lee, S.-B.; Vlassak, J.J. Effects of stretching and cycling on the fatigue behavior of polymer-supported Ag thin films. Mater. Sci. Eng. A 2013, 575, 86-93. [CrossRef]

97. Kreiml, P.; Rausch, M.; Terziyska, V.L.; Köstenbauer, H.; Winkler, J.; Mitterer, C.; Cordill, M.J. Correlation of mechanical damage and electrical behavior of Al/Mo bilayers subjected to bending. Thin Solid Films 2019, 687, 137480. [CrossRef]

98. Glushko, O.; Cordill, M.J.; Klug, A.; List-Kratochvil, E.J.W. The effect of bending loading conditions on the reliability of inkjet printed and evaporated silver metallization on polymer substrates. Microelectron. Reliab. 2016, 56, 109-113. [CrossRef]

99. Yi, S.M.; Choi, I.S.; Kim, B.J.; Joo, Y.-C. Reliability Issues and Solutions in Flexible Electronics Under Mechanical Fatigue. Electron. Mater. Lett. 2018, 14, 387-404. [CrossRef]

100. Lee, H.-Y.; Yi, S.-M.; Lee, J.-H.; Lee, H.-S.; Hyun, S.; Joo, Y.-C. Effects of bending fatigue on the electrical resistance in metallic films on flexible substrates. Met. Mater. Int. 2010, 16, 947-951. [CrossRef]

101. Kim, B.-J.; Shin, H.-A.-S.; Jung, S.-Y.; Cho, Y.; Kraft, O.; Choi, I.-S.; Joo, Y.-C. Crack nucleation during mechanical fatigue in thin metal films on flexible substrates. Acta Mater. 2013, 61, 3473-3481. [CrossRef]

102. Cordill, M.J.; Jörg, T.; Glushko, O.; Franz, R.; Mitterer, C. Crack deflecting microstructure for improved electro-mechanical lifetimes of flexible systems. Mater. Lett. 2019, 244, 47-49. [CrossRef]

103. Schwaiger, R.; Kraft, O. Size effects in the fatigue behavior of thin Ag films. Acta Mater. 2003, 51, 195-206. [CrossRef]

104. Sim, G.D.; Won, S.; Jin, C.Y.; Park, I.; Lee, S.B.; Vlassak, J.J. Improving the stretchability of as-deposited Ag coatings on poly-ethylene-terephthalate substrates through use of an acrylic primer. J. Appl. Phys. 2011, 109, 073511. [CrossRef]

105. Guan, Q.; Laven, J.; Bouten, P.C.P.; de With, G. Mechanical failure of brittle thin films on polymers during bending by two-point rotation. Thin Solid Films 2016, 611, 107-116. [CrossRef]

106. Kamiya, S.; Izumi, H.; Sekine, T.; Shishido, N.; Sugiyama, H.; Haga, Y.; Minari, T.; Koganemaru, M.; Tokito, S. A multidimensional scheme of characterization for performance deterioration behavior of flexible devices under bending deformation. Thin Solid Films 2020, 694, 137613. [CrossRef]

107. Cordill, M.J.; Kreiml, P. An in depth comparison of methods to evaluate bending failure for flexible electronics. Dig. Tech. Pap.-SID Int. Symp. 2021, 52, 111-114. [CrossRef]

108. Kreiml, P.; Rausch, M.; Terziyska, V.L.; Köstenbauer, H.; Winkler, J.; Mitterer, C.; Cordill, M.J. Improved electro-mechanical reliability of flexible systems with alloyed Mo-Ta adhesion layers. Thin Solid Films 2021, 720, 138533. [CrossRef] 
109. Kreiml, P.; Rausch, M.; Terziyska, V.L.; Winkler, J.; Mitterer, C.; Cordill, M.J. Compressive and tensile bending of sputter deposited $\mathrm{Al} /$ Mo bilayers. Scr. Mater. 2019, 162, 367-371. [CrossRef]

110. Andersons, J.; Modniks, J.; Leterrier, Y.; Tornare, G.; Dumont, P.; Månson, J.A.E. Evaluation of toughness by finite fracture mechanics from crack onset strain of brittle coatings on polymers. Theor. Appl. Fract. Mech. 2008, 49, 151-157. [CrossRef]

111. De Goede, J.; Bouten, P.; Médico, L.; Leterrier, Y.; Månson, J.; Nisato, G. Failure of brittle functional layers in flexible electronic devices. Mater. Res. Soc. Symp. Proc. 2005, 854, U9.2. [CrossRef]

112. Plojoux, J.; Leterrier, Y.; Månson, J.-A.E.; Templier, F. Mechanical integrity analysis of multilayer insulator coatings on flexible steel substrates. Thin Solid Films 2007, 515, 6890-6898. [CrossRef]

113. Stoney, G.G. The Tension of Metallic Films Deposited by Electrolysis. Proc. R. Soc. A Math. Phys. Eng. Sci. 1909, 82, 172-175. [CrossRef]

114. Hofer, A.M.; Schlacher, J.; Keckes, J.; Winkler, J.; Mitterer, C. Sputtered molybdenum films: Structure and property evolution with film thickness. Vacuum 2014, 99, 149-152. [CrossRef]

115. Jörg, T.; Music, D.; Hauser, F.; Cordill, M.J.; Franz, R.; Winkler, J.; Schneider, J.M.; Mitterer, C. Deformation behavior of Re alloyed Mo thin films on flexible substrates: In situ fragmentation analysis supported by first-principles calculations. Sci. Rep. 2017, 7, 7374. [CrossRef] [PubMed]

116. Jörg, T.; Music, D.; Cordill, M.J.; Franz, R.; Köstenbauer, H.; Linke, C.; Winkler, J.; Schneider, J.M.; Mitterer, C. A correlative experimental and ab initio approach to improve the fracture behavior of Mo thin films by alloying with Cu. Appl. Phys. Lett. 2017, 111, 134101. [CrossRef]

117. Etiemble, A.; Lopes, L.; Bouala, G.I.N.; Borges, J.; Malchère, A.; Langlois, C.; Vaz, F.; Steyer, P. Fracture resistance of Ti-Ag thin films deposited on polymeric substrates for biosignal acquisition applications. Surf. Coat. Technol. 2019, 358, 646-653. [CrossRef]

118. Cordill, M.J.; Kreiml, P.; Putz, B.; Trost, C.O.W.; Lassnig, A.; Mitterer, C.; Renault, P.O.; Faurie, D. Film architecture and thickness effects in biaxially strained polymer supported Al/Mo bilayers. Mater. Today Commun. 2021. submitted.

119. Woo, N.C.; Cherenack, K.; Tröster, G.; Spolenak, R. Designing micro-patterned Ti films that survive up to $10 \%$ applied tensile strain. Appl. Phys. A 2010, 100, 281-285. [CrossRef]

120. Marx, V.M.; Kirchlechner, C.; Breitbach, B.; Cordill, M.J.; Többens, D.M.; Waitz, T.; Dehm, G. Strain-induced phase transformation of a thin Co film on flexible substrates. Acta Mater. 2016, 121, 227-233. [CrossRef]

121. Marx, V.M.; Cordill, M.J.; Többens, D.M.; Kirchlechner, C.; Dehm, G. Effect of annealing on the size dependent deformation behavior of thin cobalt films on flexible substrates. Thin Solid Films 2017, 624, 34-40. [CrossRef]

122. Cordill, M.J.; Glushko, O.; Kleinbichler, A.; Putz, B.; Többens, D.M.; Kirchlechner, C. Microstructural influence on the cyclic electro-mechanical behaviour of ductile films on polymer substrates. Thin Solid Films 2017, 644, 166-172. [CrossRef]

123. Glushko, O.; Kiener, D. Initiation of fatigue damage in ultrafine grained metal films. Acta Mater. 2021, 206, 116599. [CrossRef]

124. Lu, N.; Suo, Z.; Vlassak, J.J. The effect of film thickness on the failure strain of polymer-supported metal films. Acta Mater. 2010, 58, 1679-1687. [CrossRef]

125. Olliges, S.; Gruber, P.A.; Orso, S.; Auzelyte, V.; Ekinci, Y.; Solak, H.H.; Spolenak, R. In situ observation of cracks in gold nano-interconnects on flexible substrates. Scr. Mater. 2008, 58, 175-178. [CrossRef]

126. Gruber, P.A.; Böhm, J.; Onuseit, F.; Wanner, A.; Spolenak, R.; Arzt, E. Size effects on yield strength and strain hardening for ultra-thin $\mathrm{Cu}$ films with and without passivation: A study by synchrotron and bulge test techniques. Acta Mater. 2008, 56, 2318-2335. [CrossRef]

127. Xiang, Y.; Li, T.; Suo, Z.; Vlassak, J.J. High ductility of a metal film adherent on a polymer substrate. Appl. Phys. Lett. 2005, 87, 161910. [CrossRef]

128. Onisawa, K.; Takayama, S.; Shigesato, Y.; Takahashi, T. Thin Film Transistors; Kuo, Y., Ed.; Springer: Boston, MA, USA, 2004; Volume 1, ISBN 978-1-4020-7504-9.

129. Zhang, J.Y.; Zhang, X.; Wang, R.H.; Lei, S.Y.; Zhang, P.; Niu, J.J.; Liu, G.; Zhang, G.J.; Sun, J. Length-scale-dependent deformation and fracture behavior of $\mathrm{Cu} / \mathrm{X}(\mathrm{X}=\mathrm{Nb}, \mathrm{Zr})$ multilayers: The constraining effects of the ductile phase on the brittle phase. Acta Mater. 2011, 59, 7368-7379. [CrossRef]

130. Putz, B.; Milassin, G.; Butenko, Y.; Völker, B.; Gammer, C.; Semprimoschnig, C.; Cordill, M.J. Interfacial mutations in the Al-Polyimide system. Surf. Interface Anal. 2018, 50, 579-586. [CrossRef]

131. Putz, B.; Wurster, S.; Edwards, T.E.J.; Völker, B.; Milassin, G.; Többens, D.M.; Semprimoschnig, C.O.A.; Cordill, M.J. Mechanical and optical degradation of optical solar reflectors during simulated low earth orbit thermal cycling. Acta Astronaut. 2020, 175, 277-289. [CrossRef]

132. Cordill, M.J.; Kreiml, P.; Putz, B.; Mitterer, C.; Thiaudiere, D.; Mocuta, C.; Renault, P.-O.; Faurie, D. Role of layer order on the equi-biaxial behavior of Al/Mo bilayers. Scr. Mater. 2021, 194, 113656. [CrossRef]

133. Cordill, M.J.; Jörg, T.; Többens, D.M.; Mitterer, C. Improved fracture resistance of Cu/Mo bilayers with thickness tailoring. Scr. Mater. 2021, 202, 113994. [CrossRef]

134. Kreiml, P.; Rausch, M.; Terziyska, V.L.; Köstenbauer, H.; Winkler, J.; Mitterer, C.; Cordill, M.J. Balancing the electro-mechanical and interfacial performance of Mo-based alloy films. Materialia 2020, 12, 100774. [CrossRef] 
135. Lohmiller, J.; Spolenak, R.; Gruber, P.A. Alloy-dependent deformation behavior of highly ductile nanocrystalline AuCu thin films. Mater. Sci. Eng. A 2014, 595, 235-240. [CrossRef]

136. Lohmiller, J.; Woo, N.C.; Spolenak, R. Microstructure-property relationship in highly ductile Au-Cu thin films for flexible electronics. Mater. Sci. Eng. A 2010, 527, 7731-7740. [CrossRef] 